\title{
Fundamental molecules of life are pigments which arose and co-evolved as a response to the thermodynamic imperative of dissipating the prevailing solar spectrum
}

\author{
K. Michaelian ${ }^{1}$ and A. Simeonov ${ }^{2}$ \\ ${ }^{1}$ Instituto de Física, UNAM, Circuito Interior de la Investigación Científica, Cuidad Universitaria, \\ México D.F., C.P. 04510, Mexico \\ ${ }^{2}$ Independent researcher, Bigla str. 7, Skopje, the former Yugoslav Republic of Macedonia \\ Correspondence to: K. Michaelian (karo@fisica.unam.mx) \\ and A. Simeonov (alecsime.gm@gmail.com)
}

Received: 21 July 2014 - Published in Biogeosciences Discuss.: 2 February 2015

Revised: 28 July 2015 - Accepted: 28 July 2015 - Published: 19 August 2015

\begin{abstract}
The driving force behind the origin and evolution of life has been the thermodynamic imperative of increasing the entropy production of the biosphere through increasing the global solar photon dissipation rate. In the upper atmosphere of today, oxygen and ozone derived from life processes are performing the short-wavelength UV-C and UV-B dissipation. On Earth's surface, water and organic pigments in water facilitate the near-UV and visible photon dissipation. The first organic pigments probably formed, absorbed, and dissipated at those photochemically active wavelengths in the UV-C and UV-B that could have reached Earth's surface during the Archean. Proliferation of these pigments can be understood as an autocatalytic photochemical process obeying non-equilibrium thermodynamic directives related to increasing solar photon dissipation rate. Under these directives, organic pigments would have evolved over time to increase the global photon dissipation rate by (1) increasing the ratio of their effective photon cross sections to their physical size, (2) decreasing their electronic excited state lifetimes, (3) quenching radiative de-excitation channels (e.g., fluorescence), (4) covering ever more completely the prevailing solar spectrum, and (5) proliferating and dispersing to cover an ever greater surface area of Earth. From knowledge of the evolution of the spectrum of G-type stars, and considering the most probable history of the transparency of Earth's atmosphere, we construct the most probable Earth surface solar spectrum as a function of time and compare this with the history of molecular absorption maxima obtained from
\end{abstract}

the available data in the literature. This comparison supports the conjecture that many fundamental molecules of life are pigments which arose, proliferated, and co-evolved as a response to dissipating the solar spectrum, supports the thermodynamic dissipation theory for the origin of life, constrains models for Earth's early atmosphere, and sheds some new light on the origin of photosynthesis.

\section{Introduction}

Like all irreversible processes, life must have arisen as a response to the thermodynamic imperative of dissipating a generalized thermodynamic potential. By far the most important potential that life dissipates today is the solar photon potential. Living systems reduce the albedo of Earth and dissipate, through many coupled irreversible processes, shortwave incoming radiation into long-wave radiation, which is eventually returned to space, ensuring an approximate energy balance in the biosphere. We have suggested that the optimization of this entropy production under the prevailing solar photon potential provides the motive force behind the origin and evolution of life (Michaelian, 2005, 2009, 2011, 2012a, b, 2013).

Many of the earliest organic molecules, those common to all three domains of life (Bacteria, Archaea, and Eukaryota), are pigments which absorb light in the middle ultraviolet (UV-C and UV-B) and when in an aqueous environment dis- 
sipate this light efficiently into heat. (The word "pigment", as used here, refers to a molecule that selectively absorbs at any wavelength, not only in the visible.) Over the history of life on Earth, organic pigments have evolved because they absorb in the range where water does not, approximately 220 to $700 \mathrm{~nm}$. Stomp et al. (2007) in fact demonstrated just how neatly organic pigments are filling photon niches left by water. From this thermodynamic perspective, the origin of life began with the photochemical formation of organic pigments that dissipate, at those wavelengths where water does not absorb, the solar photon potential arriving at Earth's surface. Specifically, we have postulated (Michaelian, 2009, 2011) that life began dissipating UV-C photons within the range of 240 to $280 \mathrm{~nm}$, where a window existed in the primitive Earth atmosphere (Sagan, 1973) and where the primary molecules, those common to all three domains of life (RNA and DNA, the aromatic amino acids, and enzymatic cofactors), absorb and dissipate strongly when in water.

This "thermodynamic dissipation theory for the origin of life" suggests that the evolutionary trajectory of life on Earth is, and always was, driven by increases in the global photon dissipation rate of the biosphere. This is obtained through optimizing the pigment photon dissipation at the entropically most important photon wavelengths (short wavelengths) arriving at Earth's surface by evolving (1) increases in the photon absorption cross section with respect to pigment physical size, (2) decreases in the electronic excited state lifetimes of the pigments, (3) quenching of the radiative de-excitation channels (e.g., fluorescence), (4) greater coverage of the solar spectrum, and (5) pigment proliferation and dispersion over an ever greater surface area of Earth by evolving mobile organisms that spread essential nutrients and seeds into inhospitable environments, including mid-ocean and extreme land environments (Michaelian, 2009, 2011, 2012a).

The earliest organic pigments on Earth's surface were probably formed directly via photochemical reactions on prebiotic molecules such as $\mathrm{H}_{2}, \mathrm{~N}_{2}, \mathrm{CO}_{2}, \mathrm{CH}_{4}, \mathrm{HCN}$, $\mathrm{H}_{2} \mathrm{O}$, and common polycyclic aromatic hydrocarbons (Oró and Kimball, 1961). Contemporary organic pigments have to be formed through more indirect biosynthetic routes, since high-energy photochemically active wavelengths are no longer available at Earth's surface; however, these contemporary routes are still ultimately based on photochemical reactions, but now in the visible. When in water these pigments dissipate the solar photon potential into heat and their formation can therefore be viewed as an autocatalytic dissipative process driven by entropy production. This nonlinear, non-equilibrium process results in concentrations of the pigments orders of magnitude beyond their expected equilibrium values (this has been well studied for chemical reactions (Prigogine, 1967), and we have extended it to the photochemical reactions (Michaelian, 2013)) and thus explains the proliferation of organic pigments over Earth's entire surface (Michaelian, 2011, 2013).
Nucleic acid and other fundamental pigment proliferation at the beginning of life is assumed to have been generated by the photochemical autocatalytic process as mentioned in the previous paragraph, although the detailed mechanisms of these processes are yet to be determined. In fact, Patel et al. (2015) found experimentally plausible routes to the generation of these nucleotide pigments using UV-C light. RNA molecules have also been found to catalyze the synthesis of nucleotides, i.e., their own building blocks (Unrau and Bartel, 1998).

We believe that a fundamental thermodynamic reason for the polymerization of these nucleic acids into single strands is that they could then act as stereochemical templates for the attachment of other UV-C-absorbing antenna pigment molecules (such as the aromatic amino acids which have affinity to their codons or anticodons) that could act as electronically excited donors to the RNA or DNA single-strand polymers acting as acceptors and providing rapid radiationless dissipation of the electronic excitation energy to the ground state (for example, aromatic amino acid excited state lifetimes are of the order of nanoseconds, whereas RNA or DNA excited state lifetimes are sub-picosecond). The complex of pigment+RNA/DNA would thus dissipate more UV$\mathrm{C}$ than the sum of its component parts.

A template-directed mechanism for the primordial nonenzymatic replication of RNA/DNA, which we called UVTAR (ultraviolet and temperature-assisted replication), was given in an earlier work (Michaelian, 2009, 2011). In this scenario, the local heat generated by the dissipation of a UV-C photon by the nucleic acid bases of RNA or DNA is sufficient to disrupt the hydrogen bonds between complementary bases and allow separation into single strands. This hypothesis has been supported by recent experimental data (Michaelian and Santillán Padilla, 2014) showing that shortstrand ( $<48 \mathrm{bp}$ ), double-stranded DNA effectively denatures when exposed to UV-C light. Enzyme-less extension to form a complementary strand is plausible if it were performed overnight at colder sea surface temperatures and using $\mathrm{Mg}^{2+}$ ions as cofactors. Some experimental evidence for this kind of enzyme-less extension has already been given (Szostak, 2012, and references therein).

One could look at the overall process of production and replication of RNA or DNA in terms of the individual steps or mechanisms, for example (1) autocatalytic photochemical production of the nucleic acid bases and other pigment molecules, (2) polymerization of the bases into single strands, (3) attachment of other pigment molecules to coding sections on the RNA or DNA polymers, (4) UV-C-induced denaturing, and (5) enzyme-less extension. Alternatively, one could look at the process as one large autocatalytic photochemical reaction in which the net result is the proliferation of specific (coding) RNA or DNA segments which have large photon dissipation capacity. The latter view is a more general thermodynamic view, while the former view, considering the individual steps in the overall reaction, is a more detailed 
mechanistic view. A still more detailed view of the actual mechanisms operating in each step has yet to be delineated, particularly with regard to mechanisms (routes) to the UV-C photochemical production of the pigments (point 1 above). However, the general view of the proliferation of coding segments of RNA and DNA, as an autocatalytic photochemical reaction which proceeds and evolves through thermodynamic selection based on the efficacy of the organism to dissipate the solar photon potential, is the most useful view for providing a physical-chemical description of evolution through natural selection and avoids having to include an ad hoc "will (drive) to survive" (the Darwinian postulate) in the description of evolution.

The most general trend of evolution (the hallmark of evolution) appears to be towards covering the entire surface of Earth with efficient dissipating organic pigments. Near the beginnings of life, this proliferation was attained through abiotic means (particularly using UV-C light and autocatalytic dissipative photochemical reactions), while today it is carried out through complex biosynthetic pathways but still ultimately dependent on light. The net effect has been the increase in photon dissipation, and this is being thermodynamically selected (on which natural selection must ultimately be physically grounded).

Driving the proliferation and evolution of life is thus the thermodynamic imperative of increasing the global entropy production of the biosphere. Since the bulk of the entropy production on Earth's surface consists mainly in the dissipation of solar photons by organic pigments in water, the history of absorption by organic pigments should correlate with the evolution of the surface solar photon spectrum. Based on this conjecture, in this article we first consider the most probable evolution of the solar spectrum at Earth's surface and compare this with a pigment history (a pigment tree of life) reconstructed from the available data in the literature. This comparison leads us to the conclusion that many fundamental molecules of life are organic pigments, lends strong support to the thermodynamic dissipation theory for the origin of life (Michaelian, 2009, 2011), constrains models of Earth's early atmosphere, and sheds new light on the origin of photosynthesis.

\section{Evolution of Earth's surface photon spectrum}

From the best available knowledge of the evolution of solar type stars and of the evolution of Earth's atmosphere we reconstruct here the most probable solar photon spectrum reaching Earth's surface as a function of time since the beginnings of life. In Sect. 4, this reconstruction is compared with the available data concerning the history of pigment absorption presented in Sect. 3 .

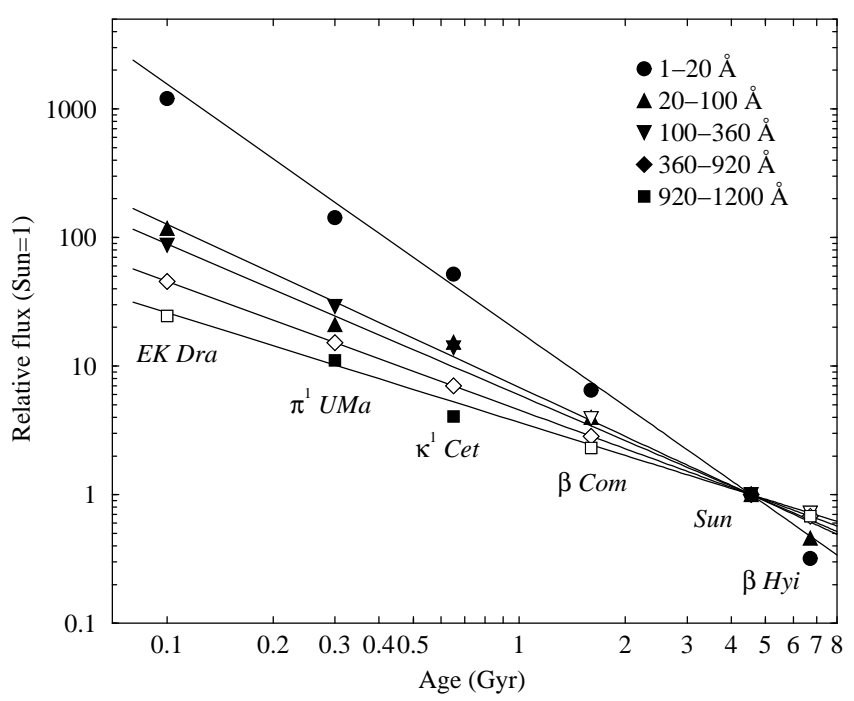

Figure 1. Solar-normalized fluxes (with respect to those of today) vs. stellar age for different wavelength bands for solar-type stars. Taken from Ribas et al. (2005).

\subsection{Evolution of the solar spectrum}

Through studying nearby spectral type $G$ and luminosity class V (G-V-type) main sequence stars similar to our Sun, of 0.8 to 1.2 solar masses and surface temperatures of between 5300 and $6000 \mathrm{~K}$, which have known rotational periods and well-determined physical properties, including temperatures, luminosities, metal abundances, and ages, Dorren and Guinan (1994) were able to reconstruct the most probable evolution of our Sun's characteristics over time, in particular the evolution of its spectral emission. This "Sun in Time" project has been carried out using various satellite-mounted telescopes including ROSAT, Chandra, Hubble, and EUVE and now has representative data for our Sun's main sequence lifetime from $130 \mathrm{Ma}$ to $8.5 \mathrm{Ga}$.

Over the lifetime of G-type main sequence stars, emitted wavelengths of shorter than $150 \mathrm{~nm}$ originate predominantly in the chromosphere and corona (stellar atmosphere) in solar flares resulting from magnetic disturbances. The high rotation rate of a young star gives it an initially large magnetic field, before significant magnetic breaking sets in, and thus intense and more frequent solar flares leading to large fluxes of these very high energy photons. In Fig. 1 the shortwavelength flux intensities as a function of the age of a Gtype star are given. From the figure it can be seen that our Sun at $500 \mathrm{Ma}$ (at the probable beginnings of life on Earth at $3.85 \mathrm{Ga}$ ) would have been 5 to 80 times (depending on wavelength) more intense at these very short wavelengths.

Wavelengths longer than $150 \mathrm{~nm}$ are known to originate on the photosphere and are emitted essentially in a blackbody spectrum (apart from a few strong stellar atmospheric absorption lines) at the star's effective surface temperature (Cnossen et al., 2007). The effective surface temperature of 
a star is related to its visible luminosity, $L_{\mathrm{S}}$, and radius, $r$, by the Stefan-Boltzmann law,

$T_{\mathrm{eff}}=\left(\frac{L_{\mathrm{S}}}{4 \pi \sigma r^{2}}\right)^{1 / 4}$,

where $\sigma$ is the Stefan-Boltzmann constant.

The luminosity of a star is an increasing function of its age because hydrogen fusion begins predominantly in the core and gradually proceeds outwards as helium "ash" settles into the core (Karam, 2003). Our Sun, at the time of the origin of life, is thus expected to have been about $30 \%$ less luminous than today. The radius of a star is also a monotonically increasing function of its age (Bahcall et al., 2001). The net result for our Sun is that its effective surface temperature has been increasing steadily and at the origin of life was approximately $1.6 \%$ less than today, while the integrated UV flux $(176-300 \mathrm{~nm})$ was most likely about $15 \%$ less than today (Karam, 2003).

\subsection{Evolution of the transparency of Earth's atmosphere}

Far more uncertain, but much more important than the incident solar spectrum in determining the solar photon flux at Earth's surface in prior times, is the wavelength-dependent extinction in the atmosphere due to both absorption and scattering. Although the exact history of the primitive atmosphere and its evolution to its present state is still under active debate, there are, fortunately, well-established geochemical data from the abiotic and biotic fossil record that constrain model scenarios.

Earth's second atmosphere of the Archean (the first atmosphere was probably lost to space during the heavy asteroid bombardment of between 4.4 and $4.2 \mathrm{Ga}$ with a late spike in bombardment at between 3.9 and $3.8 \mathrm{Ga}$; post-latelunar bombardment; Gomes et al., 2005) is thought to have been composed mainly of $\mathrm{N}_{2}, \mathrm{CO}_{2}, \mathrm{H}_{2} \mathrm{O}, \mathrm{CH}_{4}$, and some $\mathrm{NH}_{3}$, with the ratio $\mathrm{CH}_{4} / \mathrm{CO}_{2} \ll 1$ (Kasting et al., 1983; Kharecha et al., 2005), and perhaps up to 0.1 bar of $\mathrm{H}_{2}$ (Tian et al., 2005), but with very little oxygen and therefore essentially no ozone. For commonly assumed Archean atmospheric pressures of around 1 bar, these gases are all nearly perfectly transparent above approximately $220 \mathrm{~nm}$ (Sagan, 1973). However, considering probable volcanic outgassing of hydrogen sulfide (the most thermodynamically probable sulfur-containing gas under reducing conditions; Miller, 1957; Sagan and Miller, 1960) from many active vents and the likely formation rates of aldehydes (formaldehyde and acetaldehyde) through UV photochemical reactions on hydrogen sulfide, Sagan (1973) calculated a 240 to $290 \mathrm{~nm}$ window of transparency in the UV for Earth's atmosphere at the beginning of life. The two above mentioned aldehydes would have caused strong extinction from $290 \mathrm{~nm}$ to approximately $320 \mathrm{~nm}$ (Sagan, 1973).
The oxygen isotope content in zircon crystals betrays the existence of liquid water on Earth's surface since well before the beginning of life (Mojzsis et al., 2001). However, as stated above, the standard solar model and observational data on stars similar to our Sun suggest that the wavelength integrated luminosity of our Sun was as much as $30 \%$ less at the beginnings of life (Sagan and Chyba, 1997), which is inconsistent with the presence of liquid water unless one accepts a strong greenhouse atmosphere or a very different evolutionary model for our Sun, such as an early high mass-loss rate (Guzik et al., 1987) or a pulsar-centered Sun (Michaelian and Manuel, 2011). The most probable greenhouse gases are carbon dioxide, water vapor, methane, and ammonia. Lowe and Tice (2004) presented geologic data suggesting that the Earth was kept warm by $\mathrm{CO}_{2}$ and $\mathrm{CH}_{4}$ at ratios of $\mathrm{CH}_{4} / \mathrm{CO}_{2} \ll 1$, maintaining surface temperatures around $80^{\circ} \mathrm{C}$ at $3.8 \mathrm{Ga}$ (Knauth, 1992; Knauth and Lowe, 2003) and falling to $70 \pm 15^{\circ} \mathrm{C}$ at $3.5-3.2 \mathrm{Ga}$ (Lowe and Tice, 2004). Ammonia is very susceptible to UV destruction, and therefore it is not considered to have been a major component of Earth's atmosphere during the Archean (Sagan, 1973).

Using a model based on the present spectral emission of the G-V star $\kappa^{1}$ Cet (HD 20630) of an estimated age of $0.5 \mathrm{Ga}$, the age of the Sun at the beginning of life (3.95$3.85 \mathrm{Ga}$ ), and the Beer-Lambert law for atmospheric absorption but without considering multiple scattering, Cnossen et al. (2007) showed that wavelengths below about $200 \mathrm{~nm}$ would have been strongly extinguished by $\mathrm{N}_{2}, \mathrm{H}_{2} \mathrm{O}$, and $\mathrm{CO}_{2}$ in the atmosphere. In their estimation, at no time in Earth's history would its surface have been subjected to radiation shorter than $200 \mathrm{~nm}$. There is, however, some contradictory evidence in mass-independent sulfur isotopic signatures, suggesting that wavelengths as short as $190 \mathrm{~nm}$ may have penetrated to low altitudes in the Earth's early atmosphere, at least until about $2.45 \mathrm{Ga}$ (Farquhar et al., 2001).

The calculation by Cnossen et al. (2007) for the photon flux intensity at $260 \mathrm{~nm}$, where RNA and DNA absorb strongly, is approximately $1 \times 10^{-2} \mathrm{~W} \mathrm{~m}^{-2} \mathrm{~nm}^{-1}$ (or $1.4 \times 10^{12}$ photons s $\mathrm{s}^{-1} \mathrm{~cm}^{-2} \mathrm{~nm}^{-1}$ ), which, although seemingly small, is roughly $10^{31}$ times greater than what it is today due to the absorption at this wavelength by ozone and oxygen in today's atmosphere (Cnossen et al., 2007). Considering only absorption based on the predicted amount of oxygen in the atmosphere, and the expected cross section for photochemical production of ozone, Karam (2003) predicted a somewhat higher photon flux at $260 \mathrm{~nm}$ of approximately $1 \times 10^{13}$ photons s $\mathrm{s}^{-1} \mathrm{~cm}^{-2} \mathrm{~nm}^{-1}$. Sagan (1973) calculated an integrated flux of light reaching Earth's surface of wavelength $\leq 290 \mathrm{~nm}$ of approximately $3.3 \mathrm{~W} \mathrm{~m}^{-2}$ and estimated that such a flux would be lethal to today's organisms in under $0.3 \mathrm{~s}$.

Although $\mathrm{CO}_{2}, \mathrm{H}_{2} \mathrm{O}$, and the other primordial gases would have absorbed almost all of the very high energy incident photons $(<200 \mathrm{~nm})$ coming from an early Sun (see Fig. 1) of age $<0.5 \mathrm{Ga}$, this light still has some relevance 
to the spectrum at Earth's surface since some photons would have Compton-scattered into energies within the atmospheric window of transparency of between 240 and $290 \mathrm{~nm}$ and be available at the surface of Earth for absorption by the early organic pigments. Employing calculations by Smith et al. (2004), Cnossen et al. (2007) estimate that the contribution of Compton-scattered X-ray photons into an atmospheric window of 200-300 nm would have provided an additional $\sim 10^{-6}-10^{-5} \mathrm{Wm}^{-2} \mathrm{~nm}^{-1}$, with the scattering of still higher-energy gamma rays into the window increasing this only slightly.

Lowe and Tice (2004) suggested a gradual depletion of atmospheric $\mathrm{CO}_{2}$ through the carbonate-silicate geochemical cycle starting around 3.2-3.0 Ga through weathering of the newly forming continental crust, including the Kaapvaal and Pilbara cratons. By 2.9-2.7 Ga, $\mathrm{CH}_{4} / \mathrm{CO}_{2}$ ratios may have become $\sim 1$, thereby stimulating the formation of an organic haze that would have given rise to a large visible albedo and reducing surface temperatures to below $60^{\circ} \mathrm{C}$ at $2.9 \mathrm{Ga}$, perhaps allowing oxygenic photosynthetic organisms to thrive and increasing the amount of oxygen and ozone in the atmosphere (Lowe and Tice, 2004). Pavlov et al. (2000) showed that 1000 ppmv each of $\mathrm{CH}_{4}$ and $\mathrm{CO}_{2}$ (Kharecha et al., 2005) would counteract the faint young Sun sufficiently to keep temperatures above freezing at this time. However, not all of Earth may have remained above freezing, since glacial tillites have been identified in the $\sim 2.9$ Ga Pongola and Witwatersrand supergroups of South Africa (Young et al., 1998; Crowell, 1999). Eventual erosion of the continents and tectonic recycling of $\mathrm{CO}_{2}$ would have allowed the $\mathrm{CH}_{4} / \mathrm{CO}_{2}$ ratio to reduce again, bringing back a warm greenhouse atmosphere to the late Archean.

Using as a model the results obtained from the Cassini/Huygens mission for Titan, Trainer et al. (2006) investigated the probable formation of organic haze on an early Earth through photolysis of $\mathrm{CH}_{4}$ with the solar Lyman- $\alpha$ line at $121.6 \mathrm{~nm}$ in a $\mathrm{N}_{2}$ and $\mathrm{CO}_{2}$ atmosphere. In laboratory experiments designed to simulate Earth's atmosphere at the origin of life, in which the $\mathrm{CH}_{4}$ mixing ratio was held at $0.1 \%$, and the $\mathrm{CO}_{2}$ mixing ratio was varied from 0 to $0.5 \%$ (suggested to include most reasonable estimates for the early Earth; Pavlov et al., 2000), they found principally molecules with mass-over-charge ratios $(\mathrm{m} / \mathrm{z})$ around $39,41,43$, and 55 , indicative of alkane and alkene fragments. The amount of aromatics of 77 and $91 \mathrm{amu}$ decreased with increasing $\mathrm{CO}_{2}$. The $\mathrm{C} / \mathrm{O}$ ratio rather than the absolute concentrations of $\mathrm{CH}_{4}$ and $\mathrm{CO}_{2}$ was shown to be the factor most correlated with the chemical composition of the products. Aerosol production was seen to be maximum at $\mathrm{C} / \mathrm{O}$ ratios close to 1 , which according to Lowe and Tice (2004) would have occurred at approximately $2.9 \mathrm{Ga}$. Approximately spherical particles were found in the experiments with average diameters of about $50 \mathrm{~nm}$. Particles of this size, at the estimated photochemical production rates, would have produced an optically thick layer in the UV but a rather thin layer in the visi- ble (Trainer et al., 2006). However, as observed on Titan, and in laboratory experiments employing an electrical discharge source, these particles readily form fractal aggregates of size $>100 \mathrm{~nm}$, consistent with observations of the atmosphere of Titan, thereby significantly increasing the visible attenuation with respect to the UV (Trainer et al., 2006).

Given the intensity of the Lyman- $\alpha$ line $(121.6 \mathrm{~nm})$ from hydrogen in the Sun at Earth's upper atmosphere and the probable concentrations of $\mathrm{CH}_{4}$ at these altitudes, Trainer et al. (2006) estimate an aerosol production rate on early Earth of between $1 \times 10^{13}$ and $1 \times 10^{15} \mathrm{~g} \mathrm{yr}^{-1}$, which alone is comparable to, or greater than, the estimated delivery of prebiotic organics from hydrothermal vents and comet and meteorite impacts combined. The free energy in UV-C surface light during the Archean available for the production of the fundamental biomolecules from primordial gases would have been many orders of magnitude greater than that available through the chemical potential at hydrothermal vents.

From studying the sulfur isotope record, DomagalGoldman et al. (2008) suggested that a thick organic haze, which blocked UV light in the 170-220 nm range from the photolysis of $\mathrm{SO}_{2}$ in the lower atmosphere, arose at $3.2 \mathrm{Ga}$ and persisted until $2.7 \mathrm{Ga}$. Based on these isotope ratios, they suggest that Earth's atmosphere went from a haze-less to thick haze between 3.2 and $2.7 \mathrm{Ga}$, and then again to a thin haze after $2.7 \mathrm{Ga}$. The appearance of the haze may be associated with the appearance of methanogens (and anoxygenic photosynthesizers) around $3.2 \mathrm{Ga}$, which led to a buildup of $\mathrm{CH}_{4}$, while continent erosion led to a decline in $\mathrm{CO}_{2}$, and as the ratio of $\mathrm{CH}_{4} / \mathrm{CO}_{2}$ became close to 1 , the organic haze became thicker and spread over the upper atmosphere.

Crowe et al. (2013) suggest that there were appreciable levels of atmospheric oxygen $\left(3 \times 10^{-4}\right.$ times present levels $)$ about 3 billion years ago, more than 600 million years before the Great Oxidation Event and some 300-400 million years earlier than previous indications for Earth surface oxygenation. The researchers also suggest that the observed levels are about 100000 times higher than what can be explained by regular abiotic chemical reactions in Earth's atmosphere, and therefore the source of this oxygen was almost certainly biological.

There is evidence of oxygenic photosynthesis by at least $\sim 2.78 \mathrm{Ga}$ in the presence of $2-\alpha$-methyl hopanes from $\mathrm{O}_{2}$ producing cyanobacteria (Brocks et al., 1999) and sterols from $\mathrm{O}_{2}$-requiring eukaryotes (Summons et al., 1999) in sediments of this age (Brocks et al., 2003). The buildup of oxygen consumed the $\mathrm{CH}_{4}$ in the atmosphere, leading to a reduction in the organic haze. The oxygenation of Earth's atmosphere may have begun in earnest at about $2.9 \mathrm{Ga}$ but accelerated at about $2.45 \mathrm{Ga}$ and would have removed most of the $\mathrm{CH}_{4}$ greenhouse gas from the atmosphere by about 2.22.0 Ga (Rye and Holland, 1998).

Other lines of geochemical evidence suggest that the major oxygenation event occurred in the atmosphere at about $2.2 \mathrm{Ga}$, with atmospheric $\mathrm{O}_{2}$ levels rising sharply from $<1 \%$ 
of present atmospheric levels to about $15 \%$ of present atmospheric levels, during a relatively short period from 2.2 to 2.1 Ga (Nisbet and Sleep, 2001; Wiechert, 2002). Studies of carbon deposition rates and the sulfur isotope record suggest another abrupt rise in atmospheric oxygen occurring at about $0.6 \mathrm{Ga}$, which probably reached present-day levels (Canfield and Teske, 1996). Deep ocean environments, on the other hand, are thought to have remained anoxic and highly sulfidic during the long geological period from 2.2 to $0.6 \mathrm{Ga}$, when atmospheric $\mathrm{O}_{2}$ was only about $15 \%$ of present-day levels (Anbar and Knoll, 2002).

The spawning of wildfires requires an atmospheric oxygen content of at least $13 \%$, and the first evidence of charcoal deposits comes from the Silurian at $420 \mathrm{Ma}$ (Scott and Glasspool, 2006). Recent results from the analysis of plant material trapped in amber suggest that oxygen levels did not rise to present-day levels of $21 \%$ by mass until very recently, remaining at levels of between 10 and $15 \%$ from 250 to $30 \mathrm{Ma}$ (Tappert et al., 2013).

Through an analysis of the imprint of "fossil raindrops" from $2.7 \mathrm{Ga}$ discovered in Ventersdorp in the North West Province of South Africa, Som et al. (2012) concluded that atmospheric pressure in the Archean was probably similar to today's and certainly no more than twice as large as today.

The amount of water in the present-day hydrologic cycle, and thus in today's atmosphere, has been predicted to rise by about $3.2 \%$ for every $1 \mathrm{~K}$ increase in surface temperature due to greenhouse warming (Kleidon and Renner, 2013). Another determination can be made from the saturation pressure of water which increases about $6.5 \%$ per degree. With temperatures in the Archean at least $50^{\circ} \mathrm{C}$ above those of today, a conservative estimate for the amount of water vapor in the atmosphere would be at least twice as large as today.

\section{The organic pigment tree of life}

The evolutionary history of organic pigments is a subject that has barely been considered hitherto but which is crucial for framing life and evolution within the proposed thermodynamic context. From this thermodynamic perspective, one would expect the history of pigment appearance and evolution to be correlated with the evolution of the solar spectrum at Earth's surface.

It is probable that the evolution of organic pigments would have kept pace with the evolving transparency of Earth's atmosphere and that there should be a continuity over time of solar photon absorption and dissipation, reflecting the Earth's surface solar spectrum, from the earliest molecules of life (nucleotides, amino acids, organic cofactors) to present-day phototropic organisms with their extensive array of pigments. It is proposed here that an important hallmark of the evolution of life on Earth is the proliferation of organic pigments over Earth's surface and their structuring in response to changes of the entropically most intense part of the pre- vailing surface solar spectrum. This continuous history of pigment proliferation and re-structuring can be resolved into stages, and we chose six basic stages which roughly correlate with particular geological eons supporting particular atmospheric transparencies.

\subsection{World of earliest pigments (Hadean eon, $\sim$ 4.6-4.0 Ga)}

The presence of both liquid and gaseous water phases 4.3 billion to 4.4 billion years ago (Mojzsis et al., 2001) implies the existence of a primitive water cycle with the probable involvement of organic pigments (Michaelian, 2009). It is generally believed that various pre-biotic inorganic and organic substances such as $\mathrm{H}_{2}, \mathrm{~N}_{2}, \mathrm{HCN}, \mathrm{CO}_{2}, \mathrm{CH}_{4}$, and polycyclic aromatic hydrocarbons were abundant in this early aquatic environment and that UV light and lightning acting on these molecules could have led to more complex organics (Miller, 1953; Cleaves et al., 2008). Whether the origin of the prebiotic organic material was predominantly terrestrial or extraterrestrial is irrelevant to the main premise of this paper. Complex organic molecules are, in fact, ubiquitous throughout the cosmos and are formed basically by the action of UV light on simpler prebiotic organic and inorganic carbon compounds (Callahan et al., 2011; Kwok, 2009; Gerakines et al., 2004).

Many species of organic molecules (especially those with conjugated systems - Zollinger, 2003) when dissolved in water are very efficient absorbers and dissipaters of UV and visible photons and should therefore be considered as organic pigments during the Hadean and Archean eons. Fast internal conversion through a conical intersection in polyatomic molecules is a result of the coupling of the electronic modes to the vibrational modes, in particular through those attributed to the $\mathrm{OH}$ and $\mathrm{CH}$ groups (Vekshin, 2002). The vibrational energy is then dissipated and channeled via intermolecular vibrational energy transfer to nearby hydrogen bonds between water molecules fomenting evaporation.

These properties would have given them excellent entropy producing capacity, and therefore it is probably not a coincidence that the fundamental molecules of life (nucleic acids, aromatic amino acids, enzymatic cofactors) are actually organic pigments in the UV-C-UV-B range. These molecules, which are at the foundations of life today, could have floated on the surface of the primordial ocean in monomeric or single-strand polymeric form, absorbing and dissipating UV and visible solar photons, transferring this energy to surrounding water molecules, and enhancing in this manner the early water cycle and Earth's global entropy production in its solar environment (Michaelian, 2012a).

In support of this conjecture is the fact that the five naturally occurring nucleic bases (adenine, guanine, thymine, cytosine, uracil) are UV pigments which absorb in the 240 $290 \mathrm{~nm}$ UV region, the short-wavelength part of the solar spectrum, which could have penetrated Earth's early Hadean 
and Archean atmosphere (Sagan, 1973), dissipating this radiation into heat with sub-picosecond singlet excited state lifetimes (Pecourt et al., 2000; Middleton et al., 2009). Another interesting and corroborating fact is that their nonnatural tautomers have much longer decay times (SerranoAndrés and Merchán, 2009; Gustavsson et al., 2006; CrespoHernández et al., 2004), implying much lower entropy producing efficacy and photochemical stability. Furthermore, it has been demonstrated that the guanine-cytosine WatsonCrick base pairs exhibit superior photon dissipation characteristics compared to other possible base pairings between these nucleobases (Abo-Riziq et al., 2005). Woutersen and Cristalli (2004) found that vibrational relaxation of the NHstretching mode occurs much faster in the adenine-uracil Watson-Crick base pairs compared to isolated monomeric uracil and that the hydrogen bonding between these bases is responsible for the extremely fast vibrational relaxation in the base-pair system. Therefore, the coupling of nucleobase photon dissipation to the water cycle and the resulting increase in entropy production can be seen as the thermodynamic driving force for their polymerization into RNA/DNA and the ensuing replication of these polymers through an ultraviolet and temperature-assisted RNA/DNA reproduction (UVTAR; Michaelian, 2009, 2011).

Other complex issues, like the homochirality of life (righthandedness of the natural RNA and DNA enantiomers and the left-handedness of amino acid enantiomers) and an explanation for the beginnings of information storage within DNA (related to the chemical affinity of aromatic amino acids to particular nucleobase sequences) can also be resolved within the scope of this thermodynamic view (Michaelian, 2011).

In addition to nucleic acids, various other organic UVC-UV-B-absorbing pigments could have proliferated on the surface of the Hadean ocean driven to high concentration by their photon dissipation capabilities (Michaelian, 2013). UV-C-UV-B light must have acted as a selective force (Sagan, 1973; Mulkidjanian et al., 2003; Serrano-Andrés and Merchán, 2009), not only for stability but also for photon dissipation characteristics, and this was probably the onset of an evolution through a thermodynamic natural selection. Among the contemporary, more universal biological molecules, aromatic amino acids (phenylalanine, tyrosine, tryptophan, histidine), cystine (Pace et al., 1995; Edelhoch, 1967); pteridine (pterin and flavin), pyridine, quinone, porphyrin, and corrin cofactors; and different isoprenoids (Crounse et al., 1963) all absorb in the UV-C-UV-B, and some of them in the visible as well (see Table 1).

The organic heterocyclic and aromatic cofactors thiamine, riboflavin, folic acid, nicotinamide, pyridoxine, ubiquinone, phytomenadione, hydroxocobalamin, and heme are essential part of the metabolism shared by all three domains of life (Raffaelli, 2011; Caetano-Anollés et al., 2012). Nicotinamide and riboflavin come in the form of nucleotides in coenzymes such as NAD (nicotinamide adenine dinucleotide) and FAD (flavin adenine dinucleotide), and because of their resem- blance to DNA/RNA nucleotides (cyclic nitrogenous base attached to pentose-phosphate moiety), they have been proposed as molecular relics from an ancient "RNA world" (White, 1976; Kyrpides and Ouzounis, 1995). The cyclic tetrapyrrole cofactor hydroxocobalamin also contains a nucleotide loop in its structure (5,6-dimethylbenzimidazole ribonucleotide), and because of its involvement in basic metabolic reactions, such as DNA synthesis, it has also been implied as one of the most ancient cofactors (Holliday et al., 2007), which, in our view, might betray the very early association between nucleic acids and tetrapyrroles in the evolutionary history of life.

Because of their strong absorbances across the UV and visible and proposed early connection with nucleic acids at the time of the origin of life (Kyrpides and Ouzounis, 1995), it is conceivable that the pre-cofactor function of these molecules was absorption and dissipation of the available UV and visible solar photons. There is consistency in that they all absorb from 220 to $290 \mathrm{~nm}$ (except for histidine) and beyond $320 \mathrm{~nm}$ but not between 290 and $320 \mathrm{~nm}$ as would be expected if the atmospheric aldehydes were absorbing there (Sagan, 1973). Apart from their UV-C-UV-Babsorbing characteristics, pterin and flavin coenzymes are known to be photochemically active chromophores in a number of actual photoenzymes and sensory photoreceptor proteins (Kritsky et al., 1997, 2010), suggesting a continuity of function since their first appearance near the origin of life. Examples are pterin- and flavin-based photoreceptor proteins called cryptochromes and phototropins in plants which mediate plant phototropism (Brautigam et al., 2004) and the pigment cyanopterin which functions as a UV/blue photoreceptor in cyanobacterial phototaxis (Moon et al., 2010). The cofactor component of these photoreceptor proteins is actually responsible for the absorption of incident visible and UV photons and they have even been proposed as ancient prechlorophyll photosynthetic pigments (Kritsky et al., 2013a, b). The amino acid tryptophan has been found to play a similar role of sensing UV-B light in the UVR8 plant photoreceptor (Christie et al., 2012).

Several abiotic syntheses routes for the nucleobases and organic cofactors have been devised using UV light. Powner et al. (2009) showed the feasibility of ribonucleotide production under plausible prebiotic conditions (bypassing the difficult production of ribose and free pyrimidine nucleobases separately) by employing UV light at $254 \mathrm{~nm}$ and a heating and cooling cycle which enhanced ribonucleotide synthesis over other less endergonic products. Bernstein et al. (1999) obtained quinones from polycyclic aromatic hydrocarbons (PAHs) in water ice which was exposed to UV radiation under astrophysical conditions. Nicotinamide (Dowler et al., 1970; Cleaves and Miller, 2001), pyridoxal (Austin and Waddell, 1999) and flavin-like compounds (Heinz et al., 1979; Heinz and Ried, 1981, 1984) have also been obtained in experiments under prebiotic conditions. 
Table 1. Molar extinction coefficients at maximum absorption of the nucleobases, aromatic amino acids, and organic heterocyclic and aromatic cofactors common to all three domains of life.

\begin{tabular}{lrr}
\hline $\begin{array}{l}\text { Common pigments to all } \\
\text { three domains of life }\end{array}$ & $\begin{array}{r}\text { Absorbance } \\
\text { maximum }(\mathrm{nm})\end{array}$ & $\begin{array}{r}\text { Molar extinction } \\
\text { coefficient }\left(\mathrm{cm}^{-1} \mathrm{M}^{-1}\right)\end{array}$ \\
\hline Adenine $^{\mathrm{a}}$ & 261 & 13400 \\
Guanine $^{\mathrm{a}}$ & $243,272.75$ & 10700,13170 \\
Thymine $^{\mathrm{a}}$ & 263.8 & 7900 \\
Cytosine $^{\mathrm{a}}$ & 266.5 & 6100 \\
Uracil $^{\mathrm{a}}$ & 258.3 & 8200 \\
Phenylalanine $^{\mathrm{b}}$ & 257.5 & 195 \\
Tyrosine $^{\mathrm{b}}$ & 274.2 & 1405 \\
Tryptophan $^{\mathrm{b}}$ & 278 & 5579 \\
Histidine $^{\mathrm{b}}$ & 211 & 5700 \\
Thiamine $^{\mathrm{c}}$ & 235,267 & 11300,8300 \\
Riboflavin $^{\mathrm{d}}$ & $263,346,447$ & $34845,13751,13222$ \\
Folic acid $^{\mathrm{e}}$ & $256,283,368$ & $26900,25100,9120$ \\
Nicotinamide $^{\mathrm{f}}$ & 262 & 2780 \\
Pyridoxine $^{\mathrm{g}}$ & 253,325 & 3700,7100 \\
Ubiquinone- $^{\mathrm{n}} \mathrm{C}^{\mathrm{h}}$ & 275 & 14240 \\
Phytomenadione $^{\mathrm{i}}$ & $248,261,270$ & $18900,-,-$ \\
Hydroxocobalamin $^{\mathrm{j}}$ & $277.75,361,549.75$ & $15478,27500,8769$ \\
Heme A $^{\mathrm{k}}$ & $430,532,584$ & $118000,8200,27000$ \\
\hline
\end{tabular}

${ }^{\text {a }}$ Fasman (1975); Callis (1979); Du et al. (1998); Dixon et al. (2005); ${ }^{\mathrm{b}}$ Fasman (1976); Du et al. (1998); Dixon et al. (2005); ${ }^{c}$ Sigma-Aldrich, product information; ${ }^{d}$ Koziol (1966); Du et al. (1998); Dixon et al. (2005); ${ }^{\mathrm{e}}$ Sigma-Aldrich, product information; ${ }^{\mathrm{f}}$ McLaren et al. (1973); ${ }^{\mathrm{g}}$ Glick (1964); ${ }^{\mathrm{h}}$ Podda et al. (1996); ${ }^{\mathrm{i}}$ Suttie (2009); Nollet (2012); ${ }^{\mathrm{j}}$ Hill et al. (1964); Pratt and Thorp (1966); Fugate et al. (1976); Du et al. (1998); Dixon et al. (2005); ${ }^{\mathrm{k}}$ Caughey et al. (1975)

Pigment-catalyzed evaporation may have led to increased concentration of organics and ions in the sea surface layer, thus promoting molecular interactions. In this manner an early association through chemical affinity between the replicating nucleic acids and other pigment molecules is plausible. Yarus et al. (2009) provide experimental evidence for a stereochemical era during the evolution of the genetic code, relying on chemical interactions between amino acids and the tertiary structures of RNA binding sites. According to their results a majority (approximately $75 \%$ ) of modern amino acids entered the code during this stereochemical era; nevertheless, only a minority (approximately $21 \%$ ) of modern codons and anticodons retain clear vestiges of these original RNA binding sites. Interestingly, the binding site for the aromatic amino acid tryptophan is among the simplest of the amino acid binding sites known, as well as selective among hydrophobic side chains, and there is a recurring CCA sequence (a tryptophan anticodon triplet) which apparently forms one side of the binding site (Majerfeld and Yarus, 2005). Moreover, Polyansky and Zagrovic (2013) provide strong evidence for the stereochemical foundation of the genetic code and suggest that mRNAs and cognate proteins may in general be directly complementary to each other and associate, especially if unstructured. Their results show that of all 20 proteinogenic amino acids, tryptophan has the highest binding affinity for purines, and histidine has the highest binding affinity for pyrimidines, followed by phenylalanine and tyrosine.

Toulmé et al. (1974) tested the binding of tryptophancontaining small peptides to heat-denatured and UVirradiated DNA, which resulted in direct stacking interaction between the indole ring of tryptophan and singlestranded regions of DNA, which lead to tryptophan fluorescence quenching, and also a preferential binding of the peptide to thymine dimers which photosensitized the splitting of the dimer, possibly acting as a primordial photolyase enzyme. The quenching of one molecule by another is accomplished through the population of the vibrational levels of the quencher molecule, in much the same way as internal conversion on single molecules (Vekshin, 2002).

Mayer et al. (1979) tested oligopeptides containing tyrosyl, lysyl, and alanyl residues which bind to polynucleotides and found that tyrosyl fluorescence of the peptides is quenched in their complexes with both single-stranded and double-stranded nucleic acids. An energy transfer mechanism from tyrosine to nucleic acid bases was proposed to account for fluorescence quenching in oligopeptide complexes with double-stranded DNAs. They further theorize that, due to the specificity of its stacking interaction for single-stranded nucleic acid structures, tyrosine might be involved through such interactions in the selective recognition of single strands by proteins. 
These data give clues as to the origin of the genetic code. It is plausible that the initial association of nucleic acids was with small peptides containing aromatic amino acids which bound preferentially to specific DNA/RNA sites, thus forming symbiotic-like systems in which nucleobases provided fluorescence quenching through internal conversion of the excited aromatic amino acid residues, and the peptides provided a larger UV-C-UV-B photon absorption cross section and primitive enzymic functions, like the splitting of thymine dimers. Apart from the increased dissipation of the coupled system, the larger cross section afforded by aromatic amino acids and cofactor molecules would produce more local heating, favoring denaturation of DNA/RNA in an ever colder sea, thus fomenting replication and so maintaining and even incrementing entropy production through photon dissipation (Michaelian, 2009, 2011).

\subsection{World of primitive pigment complexes (early Archean eon, 4.0-3.8 Ga)}

The cooling of the ocean throughout the Archean probably became an important selective force along with photon dissipation in organic pigment evolution, which induced further association of the aromatic amino acids and other pigment molecules with DNA or RNA and growth in complexity of these structures. In order for denaturing, replication, and resulting proliferation of the UV-absorbing DNA/RNA polymers to persist in ever colder waters, their auxiliary set of light-harvesting antenna pigments (small peptides and cofactor molecules) had to enlarge and grow in complexity by acquiring primitive enzymatic functions. Michaelian (2011) argues how the thermodynamic driving force of maintaining and even increasing entropy production in ever colder seas most probably fomented the appearance of information content on RNA/DNA and the associated need for their reproductive fidelity. Toulmé et al. (1974) showed how tryptophan-containing peptides might have played an enzymic role in the maintenance of this fidelity by acting as primitive photolyase enzymes. Goldfarb et al. (1951) estimated that each peptide bond contributes an average of about 2500 to 2800 to the molar absorption coefficient of proteins at $250 \mathrm{~nm}$, and this was probably the thermodynamic reason for the prebiotic synthesis of polypeptides and their association with RNA and DNA under high UV-C and UV-B light conditions of the early Archean.

By this stage, one can imagine the appearance of primitive virus-like vesicles, made of nucleic acid interior (core) and an envelope (shell) made of enzymically active, but still photon-dissipating, proteins and other smaller pigment molecules, with simple metabolic reactions between them and the surrounding dissolved ions and molecules. Biochemist Sidney Walter Fox and coworkers (Fox and Kaoru, 1958) synthesized protein-like chains dubbed "proteinoids" from a mixture of 18 common amino acids at $70^{\circ} \mathrm{C}$ in the presence of phosphoric acid. When present in certain concen- trations in aqueous solutions, proteinoids form small structures called microspheres, protobionts, or protocells. They bear many of the basic features provided by cell membranes. Evreinova et al. (1974) were able to produce stable proteinnucleic acid-carbohydrate coacervate drops stabilized by quinones, which also absorb in the UV-C (see Table 1).

Proteinoid-based protocells enclosing DNA/RNA molecules could have been the first cellular life forms on Earth. The association of these amino acid proteinoid chains around a central RNA or DNA was again thermodynamically driven by the increase in the photon cross section offered by the amino acids taking advantage of the much superior dissipation characteristics of the RNA and DNA molecules, providing sub-picosecond de-excitation of these photon-excited aromatic amino acids to the ground state through internal conversion.

\subsection{World of pigment-carrying protocells (early Archean eon, 3.8-3.5 Ga)}

Ancient (3.2-3.6 Ga) sedimentary rocks from the Barberton Greenstone Belt in South Africa and Swaziland and the Pilbara Craton in Western Australia have been found to contain prokaryotic microfossils (Noffke et al., 2013; Schopf, 2006). Evidence in these rocks suggests that $3.5 \mathrm{Ga}$ old prokaryotic microorganisms flourished in the form of microbial mats and stromatolites. Stromatolites represent accretionary sedimentary structures from shallow water environments, produced by the activity of prokaryotic, photoautotrophic microorganisms, living in mucilage-secreting communities known as microbial mats (Schopf, 2006).

This antiquity of autotrophic (and possibly photosynthetic) activity is further corroborated by chemical markers like the ratio of $\mathrm{C}^{13} / \mathrm{C}^{12}$ in sedimentary organic carbon (kerogen), which indicates a continuous record of biological $\mathrm{CO}_{2}$ fixation that goes back 3.5-3.8 Ga (Schidlowski, 1988, 2001). Among the earliest evidence for life on Earth is the biogenic graphite discovered in old metasedimentary rocks in western Greenland dated at about $3.7 \mathrm{Ga}$ (Ohtomo et al., 2014). Studies of isotopes have identified traces of methanogens and methanotrophs, and also of active carbon, nitrogen, and sulfur cycles dating back as early as $3.5 \mathrm{Ga}$, becoming very similar to modern cycles by about $2.7 \mathrm{Ga}$ (Nisbet and Sleep, 2001; Grassineau et al., 2001).

The last universal common ancestor (LUCA) from which all organisms now living on Earth descend is estimated to have lived some 3.5 to 3.8 billion years ago (Glansdorff et al., 2008; Doolittle, 2000). It had properties currently shared by all three domains of life, such as cellular structure with waterbased cytoplasm, enclosed by a lipid bilayer membrane; genetic code based on DNA or RNA; L-isomers of the 20 proteinogenic amino acids; ATP as an energy intermediate; and common enzymes and cofactors.

Since many more amino acids are chemically possible than the 20 found in modern protein molecules, and many 
other nucleotides are possible besides A, T, G, C, and U, Theobald (2010) put forward the possibility that LUCA was not alone but only a member of an ancient, diverse microbial community. However, a strong thermodynamic reason, consistent with our proposition, for the existence of only the nominal nucleotides and their Watson-Crick pairing is that these have non-radiative de-excitation times orders of magnitude shorter than any other nucleotides and their possible pairings, even of those energetically more favorable (AboRiziq et al., 2005; Woutersen and Cristalli, 2004).

From the optics of the thermodynamic dissipation theory for the origin and evolution of life (Michaelian, 2009, 2011), and the established facts given above, a picture of life on Earth prior $3.5 \mathrm{Ga}$ can be inferred. From the multitude of different pigment complexes, the one that gave rise to the line of the LUCA evolved to be a prokaryote-like, lipid-membrane vesicle (protocell) where the "old generation" of UV dissipaters (DNA/RNA plus some proteins) began to take on a new secondary role of information carriers and chemical catalysts, becoming genetic material, ribosomes, and enzymes, with a new function - to execute the synthesis, support, and proliferation of the "new dissipating generation of pigments" more completely covering the evolving solar spectrum available at Earth's surface.

Cellular structure provided two new fundamental conditions: their increased photon cross section for dissipation, and protection of the progressively more intricate biochemical activity from the outside environment. Because increasing amounts of visible photons were making it to the surface as volcano-produced sulfuric acid clouds similar to those on Venus today began to wane, it is probable that a "new generation" of visible light dissipaters on the cell surface, as membrane-bound light-harvesting antenna molecules, became increasingly common. Different types of organic pigments could have filled this role; however, through limiting our search to the line of the LUCA and keeping in mind the evidence of stromatolites and possible photosynthetic activity by this time, porphyrins/chlorins emerge as an interesting class of candidate pigments.

Many Urey-Miller-type experiments have readily produced oligopyrroles and porphyrins abiotically using various sources of energy, including electrical discharges (Hodgson and Ponnamperuma, 1968; Simionescu et al., 1978), UV irradiation (Szutka, 1964; Hodgson and Baker, 1967; Meierhenrich et al., 2005), and high temperatures of $70-100^{\circ} \mathrm{C}$, compatible with a prebiotic milieu (Lindsey et al., 2009). Porphyrin-like substances have even been found in meteorites (Hodgson and Baker, 1964) and Precambrian rocks (Kolesnikov and Egorov, 1977). Porphyrins, in fact, have a chemical affinity to DNA; their chromophore plane intercalates between base pairs of DNA, or they form stacked aggregates on its surface (Pasternack et al., 1991, 1993; Pasternack and Gibbs, 1996).

Siggel et al. (1996) found that amphiphilic porphyrins aggregate in aqueous media and form fibers, ribbons, tubules, and sheets. In lateral aggregates, the $S_{x}$ and $S_{y}$ components of the monomer Soret band centered around $400 \mathrm{~nm}$ are shifted to the blue and red, respectively, to yield exciton Soret bands at around 350 and $450 \mathrm{~nm}$. There is substantial enhancement of internal conversion and thus quenching of fluorescence in these aggregates as compared to individual porphyrin molecules.

Chlorophyll (a chlorin derivative, related in structure to porphyrin) is also interesting in this respect. Isolated chlorophylls are susceptible to bleaching (the opening up of the tetrapyrrole ring) particularly at $350 \mathrm{~nm}$, where there is significant absorption. However, at high concentration they form aggregates that are particularly rapid quenchers from the UV-C to the UV-A and therefore stable against photoreactions and break-up (Zvezdanović and Marković, 2008). These same authors demonstrated that an accessory pigment environment has rather little effect on chlorophyll bleaching independent of the wavelength of the light, and therefore the assignation of accessory pigments as protectors of the photosynthetic system may be misguided. It is more likely that since the Archean, porphyrins, and later "accessory" pigments, formed part of an ever larger dissipative system, performing the most relevant thermodynamic dissipation associated to life - that of converting short-wavelength photons into many long-wavelength photons.

Accordingly, primitive protocells could have acquired porphyrin molecules from UV-C and UV-B and visibledissipating aggregates in the environment, integrating them in the nucleic acid-protein complex as light-harvesting antenna pigments. The primitive cell then likely "learned" very early in its evolution how to synthesize its own endogenous porphyrin, an assumption which can be backed by the transfer-RNA-dependent aminolevulinic acid formation during chlorophyll biosynthesis in phototropic organisms, indicating that porphyrin biosynthesis is as ancient as that of proteins (Kumar et al., 1996; Jahn et al., 2006). In support of this view come recent phylogenetic tree reconstructions by Caetano-Anollés et al. (2012), which classify the short-chain dehydrogenase/oxidoreductase superfamily of enzymes (SDR) among the most ancient proteins ever used by cells. Their metabolic activities spread throughout numerous different metabolic subnetworks, of which porphyrin and chlorophyll metabolism has been shown to be the most ancient (Caetano-Anollés et al., 2012).

Further evidence for the antiquity of porphyrin-type pigments and their role in dissipation processes comes from the work of Mulkidjanian and Junge (1997). On the basis of evidence from sequence alignments between membranespanning segments of bacterial and plant proteins involved in photosynthesis (photosynthetic reaction centers and antenna complexes), they postulated the existence of a large ancestral porphyrin-carrying protein, which they describe as a primordial UV protector of the cell. UV "protection" functioned in a way that the aromatic amino acid residues of the membrane protein clustered around the porphyrin/chlorin 
molecule were primary receivers of UV quanta and transferred this excitation energy to the nearby pigment moiety which underwent fast internal conversion to the lowest singlet state releasing the photon energy in thermal energy.

Chlorophyll, common in most modern phototropic organisms, essentially plays this dissipative role. It has two excitation levels (the high-energy Soret band in the near UV and the low-energy Qy band in the red) and a photon absorbed in the Soret band dissipates extremely efficiently to the Qy band before the remaining free energy can be used in photosynthesis. Enhancement and redshift of the Qy band would provide even more efficient photon dissipation, and this is indeed a recognizable trait in a proposed evolutionary trajectory from protoporphyrin IX via protochlorophyll $c$ to chlorophyll $c$ and then to chlorophyll $a$ (Olson and Pierson, 1987; Larkum, 1991).

Mulkidjanian and Junge (1997) further theorize how at the beginning this dissipative photochemical activity in the cell functioned only in the context of UV "protection", but later mutations, which caused the loss of certain pigment components, led to obtainment of redox cofactors and a gradual transition from purely dissipative to productive photochemistry, i.e., from UV "protection" to photosynthesis. In the context of the thermodynamic dissipation theory for the origin of life, this putative pigment-carrying membrane protein, instead of being an "ancient UV protector" is more appropriately designated as the "new generation" of UV-dissipating pigments, continuing, from the nucleic and aromatic amino acids, the thermodynamic role of photon dissipation and catalysis of the water cycle. Since porphyrin/chlorin-carrying proteins are universal to all three domains of life (Georgopapadakou and Scott, 1977; Suo et al., 2007), either as chlorophyll-carrying photosystems or heme-carrying cytochromes, it is quite plausible that this primordial porphyrin-protein complex was the main dissipating unit of the LUCA protocells.

Whether UV-based anoxygenic photosynthesis powered these primitive cells or they were dependent on chemoautotrophy cannot be ascertained, although previously mentioned evidence (chemical markers, stromatolites) implies that autotrophy and $\mathrm{CO}_{2}$ fixation (possibly photoautotrophy) was well established by this time. Early emergence of photosynthetic autotrophy is consistent with the thermodynamic dissipation since it would have led to accelerated pigment proliferation and hence still greater photon dissipation (Michaelian, 2009, 2011). Heterotrophs most likely developed somewhat later than autotrophs and were probably more prevalent in deeper waters feeding on the "rain" of organic material from the surface. From a thermodynamic perspective they can be considered as "gardeners" of the autotrophs, playing a crucial role in the constant recycling of the elements needed for pigment synthesis (phosphate, nitrogen, carbon, etc.) and in facilitating their expansion into new, initially inhospitable, areas.

\subsection{World of pigment-carrying protocyanobacteria (Archean eon, 3.5-2.5 Ga)}

There is a continuity of stromatolites in the fossil record from 3.5 to $2.5 \mathrm{Ga}$, even though Archean geological units are relatively scarce when compared to those of the Proterozoic (Schopf et al., 2007). The distribution of Archean stromatolites seems to consistently parallel the estimated temporal distribution of Archean sediments that have survived to the present, in a way that most stromatolite fossils have been reported from younger rocks $(2.5-3.0 \mathrm{Ga})$ relatively abundant in the fossil record, and fewer from older rocks $(3.5-3.0 \mathrm{Ga})$ relatively scarce in the fossil record. Biogenicity of these sediments has been backed by the discovery of microscopic fossils with microbe-like morphologies typical of later, less questionable, Proterozoic microfossils: sinuous tubular or uniseriate filaments, small rod-shaped bodies, or unornamented coccoids (Schopf, 2006). Geochemical evidence from the Buck Reef Chert (250 to $400 \mathrm{~m}$ thick rock running along the South African coast) shows that it was most likely produced by the activities of phototrophic microbial communities about 3.4 billion years ago (Tice and Lowe, 2004, 2006). The same authors characterize the inhabitants of these ancient microbial communities as partially filamentous phototrophs which probably used the Calvin-BensonBassham cycle for $\mathrm{CO}_{2}$ fixation according to local carbon isotope composition. Interestingly, they failed to notice any traces of life in the deeper (> $200 \mathrm{~m}$ ) aquatic environments.

Combining this evidence with the results of Crowe et al. (2013) for the beginnings of atmosphere oxygenation would indicate that the advent of oxygenic photosynthesis was sometime prior $3 \mathrm{Ga}$, and was carried out by cyanobacteria-like organisms usually referred to in the scientific community as protocyanobacteria (Olson, 2006; GarciaPichel, 1998).

Cyanobacteria are believed to be one of the most ancient groups of organisms on this planet and among the earliest to branch off in a separate phylum (Altermann and Kazmierczak, 2003). As cyanobacteria are the only prokaryotes which carry out oxygenic photosynthesis, there is little doubt among experts today that they were responsible for the production and accumulation of oxygen and ozone in the atmosphere (Bekker et al., 2004). Oxygenic photosynthesis is distinguished by the presence of two photosystems (photosystem I and II), of which photosystem II incorporates the water-splitting complex (four oxidized manganese atoms and a calcium atom, held in place by proteins), and the utilization of water as a reductant, which generates oxygen as a waste product (Kiang et al., 2007; Allen and Martin, 2007). In contrast to oxygenic photosynthesis, anoxygenic types of photosynthesis employ only one of the two possible photosystems, lack the water-splitting complex, and utilize electron donors other than water, such as hydrogen, hydrogen sulfide, ferrous ions, and nitrite, among others (Kiang et al., 2007; Bryant and Frigaard, 2006). 
Because of the relatively higher complexity of their photosynthetic apparatus when compared to other photosynthetic bacteria (purple bacteria, green sulfur bacteria, green nonsulfur bacteria, heliobacteria) cyanobacteria have not been traditionally considered as a lineage in which photosynthesis could have developed. But recent studies by Mulkidjanian et al. (2006) and Mulkidjanian and Galperin (2013), comparing genome sequences of photosynthesis-related genes in phototropic members of diverse bacterial lineages, came to the conclusion that photosynthesis most likely had its origins in the cyanobacterial lineage and only later spread to other bacterial phyla by way of lateral gene transfer. These studies also propose that this direct ancestor of the cyanobacteria - protocyanobacteria - was an anaerobic, mat-dwelling phototroph which probably used hydrogen as a reductant and inherited its photosynthetic machinery from mutations of the earlier "UV-protective" membrane protein. The invention of the water-splitting complex came later, but not before the lateral gene transfer to other bacteria which lack it, and, according to Mulkidjanian and Junge (1997), this complex was probably formed by the trapping of Mn atoms in the cavities of earlier porphyrin-binding sites in photosystem II. Manganese ions of the type that occur in the water-splitting complex are readily oxidized by UV light of wavelengths less than $240 \mathrm{~nm}$ (Russel and Hall, 2006) and since there was no ozone to filter out the Sun's UV rays before the origin of water splitting, these excited Mn atoms probably served as electron donors to protocyanobacteria which were introduced into an ancient, aquatic Mn-containing environment, and only later incorporated them into their photosystem II (Allen and Martin, 2007; Johnson et al., 2013). It is worth mentioning that a Mn cluster with electron vacancies is able to dissipate the energy of a single UV photon through the formation of hydrogen peroxide from water (Mulkidjanian and Junge, 1997). The reaction of dioxygen production from water catalyzed by four low-energy photons of red light may have gradually developed at a later phase of protocyanobacterial evolution.

Dissipation of the intense UV radiation during this geological period could have further been enhanced by the invention of an even greater variety of UV-absorbing compounds like the contemporary UV-A- and UV-B-absorbing mycosporinelike amino acids and scytonemin (Shick and Dunlap, 2002; Castenholz and Garcia-Pichel, 2002; Ferroni et al., 2010). These pigments, widespread in modern cyanobacteria, algae, and other aquatic organisms and usually defined as UV protectants or sunscreens, are most likely remnants of Archean, protocyanobacterial, UV-dissipating pigments (Garcia-Pichel, 1998). Biosynthetically, mycosporine-like amino acids are derived from intermediates of the shikimate pathway for the synthesis of the aromatic amino acids (Shick and Dunlap, 2002; Portwich and Garcia-Pichel, 2003), while scytonemin is derived from tryptophan (Balskus et al., 2011), suggesting a later evolutionary appearance of these pigments compared to that of the aromatic amino acids.
Besides protocyanobacteria and other members of the domain Bacteria, the Archean seas were most likely also harboring the ancestors of modern domain Archaea (Wang et al., 2007; Woese and Gupta, 1981). If the ancestors of cyanobacteria were already present by $3 \mathrm{Ga}$, it is probable that the line of the LUCA had already branched into the separate domains Bacteria and Archaea at a much earlier point in time, probably as early as $3.5 \mathrm{Ga}$, or even earlier. No known member of the Archaea domain carries out photosynthesis, although some members of the class Halobacteria are photoheterotrophs which utilize light energy absorbed by the chromoprotein bacteriorhodopsin to synthesize ATP, and their carbon source is organic (Bryant and Frigaard, 2006).

Mulkidjanian and Junge (1997) hypothesize that the bacteriorhodopsin-based phototropism in Archaea might have also evolved from a "UV-protecting" precursor function, because it has been shown (Kalisky et al., 1981) that a UV quantum, channeled from the aromatic amino acid residues of the protein moiety, triggers the all-tans to 13cis isomerization of the retinal moiety in bacteriorhodopsin, followed by its return into the initial isomeric state by slow thermal relaxation. This bacteriorhodopsin-based photon dissipation in Archaea probably evolved as a complement to the chlorophyll-based dissipation in protocyanobacteria for dissipation of visible wavelengths left unabsorbed by chlorophyll (DasSarma, 2006, 2007).

\subsection{World of pigment-carrying cyanobacteria and algal plastids (Proterozoic eon, 2.5 Ga-542 Ma)}

Free oxygen is toxic to obligate anaerobic organisms and the rising concentrations during the early Proterozoic may have wiped out most of the Earth's anaerobic inhabitants at the time, causing one of the most significant extinction events in Earth's history known as the Oxygen Catastrophe (Sessions et al., 2009; Holland, 2006). Additionally the free oxygen reacted with the atmospheric methane, a greenhouse gas, reducing its concentration and thereby triggering the Huronian glaciation, possibly the most severe and longest snowball Earth episode (Kopp et al., 2005). Despite its toxicity for most anaerobes at the time, some lineages successfully adapted "learning" to use it as a terminal electron acceptor in electron transport chains, thus heralding the new age of aerobic respiration (Sessions et al., 2009; Raymond and Serge, 2006).

Biomarker evidence (the presence of long-chain 2methylhopanes) suggests that, during the early Proterozoic (Paleoproterozoic), a phytoplankton population was thriving in the ocean, consisting mainly, or entirely, of cyanobacteria (Summons et al., 1999; Falkowski et al., 2004; Canfield, 2005). Unlike other eubacterial phyla, cyanobacteria exhibit a substantially well-studied fossil record, with the earliest unequivocal cyanobacterial fossils dating back around $2.0 \mathrm{Ga}$, which come from two localities, the Gunflint iron formation and the Belcher Subgroup, both in Canada (Sergeev 
et al., 2002; Golubic and Lee, 1999; Amard and BertrandSarfati, 1997). Schirrmeister et al. (2013) suggest a concurrence of the onset of the Great Oxidation Event, the origin of cyanobacterial multicellular forms and an increased diversification rate of cyanobacteria.

The first advanced single-celled eukaryotes and multicellular life roughly coincide with the beginning of the accumulation of free oxygen in the atmosphere (El Albani et al., 2010; Falkowski and Isozaki, 2008; Baudouin-Cornu and Thomas, 2007). Currently there is no consensus regarding the origin of the first eukaryotic cell although numerous scenarios have been proposed including fusions between a bacterial and an archaeal ancestors and sometimes even serial merging events (Poole and Penny, 2007). The endosymbiotic hypothesis for the origin of mitochondria suggests that these organelles descend from an aerobic proteobacterium which survived endocytosis by the primitive eukaryotic cell, and thus became incorporated into its cytoplasm (Latorre et al., 2011; Doolittle, 2000). This symbiotic event is estimated to have happened around 1.7-2.0 Ga according to protein clock estimates (Feng et al., 1997; Emelyanov, 2001), and it is generally assumed that all the eukaryotic lineages that did not acquire mitochondria went extinct (Martin and Mentel, 2010).

Chloroplasts most likely came about from another endosymbiotic event involving engulfed cyanobacteria into the primitive mitochondria-bearing eukaryotic cell, which, like the origin of mitochondria, is considered to be a singular event in evolution (Stoebe and Kowallik, 1999; McFadden, 2001). This primary endosymbiotic event was still followed by a series of secondary and tertiary endosymbiotic events in which eukaryotic hosts engulfed eukaryotic algae, resulting in the formation of secondary plastids in some algal lineages (Cavalier-Smith, 2000; Delwiche, 1999).

Chloroplasts are the organelles of plants and algae that harbor biochemical pathways for all pigments or pigment precursors in the cell, like aromatic amino acids, heme, chlorophyll, and isoprenoids (Keeling, 2004). All primary chloroplasts belong to one of three chloroplast lineages - the glaucophyte chloroplast lineage, the rhodophyte (or red algal) lineage, and the chloroplastidan (or green algal) lineage (Ball et al., 2011). The second two are the largest, and the green chloroplast lineage is the one that contains land plants (Keeling, 2004). Glaucophyte chloroplasts contain photosynthetic pigments chlorophyll $a$, phycobilins, and phycobilisomes, small antenna-like structures organized on the outer face of thylakoid membranes that are also found in cyanobacteria (Keeling, 2004). Red algal chloroplasts contain chlorophyll $a$, phycobilins, and phycobilisomes, where the phycobiliprotein phycoerythrin is responsible for giving many red algae their distinctive red color. Green algal chloroplasts differ from glaucophyte and red algal chloroplasts in that they have lost their phycobilisomes, and contain chlorophyll $b$ instead (Kim and Archibald, 2008). Phylogenetic analyses, however, show that the common ancestor of cyanobacteria and chloroplasts had both chlorophyll $b$ and phycobilins
(Tomitani et al., 1999). The antiquity of chlorophyll $b$ and its early presence in the protocyanobacterial lineage might be backed by the fact that it has an absorption peak in the UV-C at around $258 \mathrm{~nm}$ (Zalar et al., 2007).

Shales of the early Mesoproterozoic Roper Group in northern Australia have been found to contain $1.5 \mathrm{Ga}$ old organic fossils called acritarchs, which are suspected to be unicellular eukaryotes and most probably algae by virtue of preserved cell wall and cytoskeletal structures (Javaux et al., 2001). Already by $1.2 \mathrm{Ga}$ very modern-looking and well-preserved fossils of red algae start appearing in the fossil record (Butterfield, 2000), although more recent work proposes the existence of even older fossils of filamentous algae dating back as far as 1.6 to $1.7 \mathrm{Ga}$ (Bengtson et al., 2009).

The end of the Proterozoic saw several relatively shortlived glaciations, after which multicellular eukaryotic life boomed in the oceans (Ediacara biota), paving the way for the still greater boom during the Cambrian explosion (Stanley, 2008).

Atmospheric changes during this eon led to the gradual dimming of UV-C light available at the surface, whose dissipation was being relegated from UV-C-absorbing biological pigments to biologically produced oxygen and UV photochemically produced stratospheric ozone. The reduced intensity of UV-C making it to the surface probably induced significant metabolic and pigment-related changes in the biological world. It is therefore conceivable that this was the period of diversification and proliferation of visible-absorbing pigments in cyanobacteria and their chloroplast counterparts in algae. Inside the photosynthetic apparatus, the work of primary photon receivers probably shifted from the aromatic amino acid residues of the light-harvesting antenna proteins (UV absorbers) to the (bacterio)chlorophyll pigments (visible and near-infrared absorbers). Contemporary carotenoid and phycobilin pigments, which function as accessory pigments to (bacterio)chlorophylls in photosynthesis, absorbing parts of the visible spectrum left unabsorbed by (bacterio)chlorophylls (Rowan, 1989; Nobel, 2009), probably became prevalent during this geological period.

Carotenoids (divided into carotenes and xanthophylls) are tetraterpenes (which contain eight isoprene units, i.e., 40 carbon atoms), and because of the multiple conjugated double bonds in their polyene hydrocarbon chain, unlike UVabsorbing isoprene and related isoprenoids with fewer conjugated double bonds, their absorption maxima shifts to longer wavelengths in the blue-green (Rowan, 1989; Nobel, 2009). Phytoene, a 40-carbon intermediate in the biosynthesis of carotenoids, whose synthesis from two molecules of geranylgeranyl pyrophosphate (GGPP) marks the first committed step in the biosynthesis of carotenoids, has an UV-vis absorption spectrum typical for a triply conjugated system with its main absorption maximum in the UV-B range at $285 \mathrm{~nm}$ (Crounse et al., 1963). Phytofluene, the second product of carotenoid biosynthesis formed from phytoene in a desaturation reaction leading to the formation of five conjugated 
double bonds, has an absorption spectra in the UV-A region, with maximal absorption at $348 \mathrm{~nm}$ (Crounse et al., 1963).

Phycobilins are linear tetrapyrroles, which could have evolved through the opening of the porphyrin macrocycle, as happens during their biosynthetic pathway from heme (Beale, 1993; Brown et al., 1990). The light-harvesting antennas of cyanobacteria and the chloroplasts of red algae, glaucophytes, and some cryptomonads consist of watersoluble protein-phycobilin complexes, known as phycobiliproteins (not present in green algae and higher plants), which efficiently absorb red, orange, yellow, and green wavelengths, not well absorbed by (bacterio)chlorophylls (Rowan, 1989; Nobel, 2009).

Ajlani and Vernotte (1998) showed that phycobiliproteins are not essential for the survival of cyanobacteria by constructing a viable mutant of the cyanobacterium Synechocystis PCC 6803 which lacked major photosystem II phycobilin antennas. This phenomenon, seemingly inconsistent with the Darwinian model of evolution, which suggests that organisms do not retain processes unbeneficial for their survival, finds consistency in the thermodynamic dissipation explanation of life if phycobiliproteins are seen more as dissipative structures rather than photosynthetic ones.

In addition to phycobilin- and chlorophyll-containing light-harvesting systems, cyanobacteria possess small chlorophyll-binding polypeptides, dubbed high-lightinducible polypeptides (HLIPs), which are not involved in photosynthesis and simply accumulate in the cell in response to intense light exposure and dissipate this energy to heat (Havaux et al., 2003; Montane and Kloppstech, 2000). This behavior has led biologists to ascribe a photoprotective role to this class of pigmented polypeptides, although we believe that their function might be more accurately described from the thermodynamic viewpoint as dissipaters of light and catalysts of the hydrologic cycle.

\subsection{World of pigment-carrying cyanobacteria and algal and plant plastids (Phanerozoic eon, $\sim 542$ Ma-present)}

The relatively rapid emergence and diversification of many new phyla and species of animals during the Cambrian period (542-488 Ma) is known as the Cambrian explosion or Cambrian radiation (Erwin and Valentine, 2013; Knoll and Carroll, 1999). Land plants evolved from chlorophyte algae living in shallow fresh waters, perhaps as early as 510 million years ago (Raven and Edwards, 2001). The oldest unequivocal fossils of land plants and fungi date from the late Cambrian period, around 480-460 Ma, but molecular evidence suggests that they may have colonized the land much earlier, 630 million years ago, even before the Cambrian explosion and snowball Earth events (Clarke et al., 2011, Heckman et al., 2001). The spread of the organic pigments carried by plants to land and plant fomentation of a terrestrial water cycle extending ever more inland provided the potential for another $30 \%$ of Earth's surface area to be cultivated for photon dissipation.

The chloroplasts of land plants contain the visibleabsorbing pigments: chlorophyll $a$ and $b$, different carotenes and xanthophylls, collectively known as photosynthetic pigments (Ruban, 2012), as well as the visible- and UVabsorbing flavonoids, which are phenolic secondary plant metabolites that do not participate in photosynthesis and are traditionally given UV-protective and antioxidant roles (Gould and Lister, 2006; Agati et al., 2007). Anthocyanins are flavonoid, water-soluble, vacuolar pigments, biosynthetically derived from phenylalanine, which occur in all tissues of higher plants, including leaves, stems, roots, flowers, and fruits. They absorb mainly in the green part of the spectrum, where chlorophylls and carotenoids do not absorb strongly, and may appear red, purple, or blue depending on the vacuolar pH (Hatier and Gould, 2009). Betalains are a class of red and yellow pigments derived from tyrosine, found only in plants of the order Caryophyllales, where they replace anthocyanin pigments (Stafford, 1994).

Wang et al. (2007) showed that transpiration rather than photosynthesis is the process maximized in plants. Transpiration is by far the largest water flux from Earth's continents, representing 80 to $90 \%$ of terrestrial evapotranspiration (Jasechko et al., 2013). On the basis of analysis of a global data set of large lakes and rivers, Jasechko et al. conclude that transpiration recycles $62000 \pm 8000 \mathrm{~km}^{3}$ of water per year to the atmosphere, using half of all solar free energy available on the land surface. As it is the energetically most consuming process in plants, one can assume that most photons absorbed by plant pigments are being dissipated (mainly through the process of non-photochemical chlorophyll fluorescence quenching (NPQ) - Müller et al., 2001) and transferred to the breaking of hydrogen bonds between water molecules, which then evaporate through the stomata of leaves. In this fashion, terrestrial plants play the same role as phytoplankton (cyanobacteria, diatoms, dinoflagellates) over bodies of water (Michaelian, 2011, 2012a), and their evolution and colonization of land can be interpreted as the extension of entropy production through photon dissipation and the fomentation of the hydrologic cycle over land surfaces. As we have emphasized in this paper, the same thermodynamic function was performed by the earliest organic pigments floating on the surface of the primordial Hadean ocean.

The timing of the earliest animal colonization of land surfaces is not precisely known: there are trace fossils of non-marine, possibly amphibious, arthropods on land around $450 \mathrm{Ma}$ (Johnson et al., 1994; Pisani et al., 2004), but there is also unconfirmed evidence of older arthropod traces on land around $530 \mathrm{Ma}$ (MacNaughton et al., 2002).

The influence of insects, crustaceans, and larger animals in spreading nutrients for the production of pigments, and thus photon dissipation and the water cycle, over barren land or mid-ocean areas cannot be overemphasized (Michaelian, 
2011). Doughty et al. (2013) showed how the Pleistocene Amazonian megafauna extinctions dramatically decreased the lateral flux of nutrients (particularly of phosphate) in all continents outside of Africa. Lavery et al. (2010) determined that blue whale feces contribute enormously to the distribution of iron in the Southern Ocean for the proliferation of cyanobacteria and thus the sequestering of atmospheric carbon at mid-ocean environments, a contemporary preoccupation but of secondary importance to photon dissipation.

\section{The organic pigment tree of life correlates with the evolution of the solar spectrum at Earth's surface}

Considering the abiotic and biotic events affecting Earth's atmosphere presented in Sect. 2, and assuming a black-body spectrum for the Sun in the relevant wavelength region, a coarse-grained history of the solar spectrum at Earth's surface can be derived. The calculations presented below assume a present-day black-body solar photosphere at an effective temperature of $5840 \mathrm{~K}$ with an $\mathrm{H}^{-}$stellar atmosphere absorption line centered on $500 \mathrm{~nm}$, and include the time dependence of the increase in the solar radius and increase in surface temperature as considered in Sect. 2.1. The results of the calculation are presented below and in Figs. 2 and 3.

Well before the origin of life at $3.85 \mathrm{Ga}$ and until about $2.7 \mathrm{Ga}$, the solar spectrum on Earth included a unique region of between approximately 230 and $290 \mathrm{~nm}$ of an integrated flux of $5.5 \pm 2 \mathrm{Wm}^{-2}$ midday at the Equator with the spectral distribution in this UV-C region peaking at around $260 \mathrm{~nm}$, bounded on the short-wavelength side by $\mathrm{H}_{2} \mathrm{~S}$ absorption and on the long-wavelength side by formaldehyde and acetaldehyde (both photochemical reaction products of UV light on hydrogen sulfide). From 290 to about $320 \mathrm{~nm}$, little light would have been available on the surface due to absorption of the aldehydes. From 320 to $700 \mathrm{~nm}$, beyond which water absorption becomes important (a warmer Earth would have supported a more humid atmosphere), the spectrum at Earth's surface in the Archean was probably very similar to the present-day spectrum but of about $30 \%$ lower luminosity due to a faint young Sun, providing an integrated energy flux of approximately $327 \mathrm{Wm}^{-2}$ integrated over 320 to $700 \mathrm{~nm}$ midday at the Equator. The biological world in this era consisted of the dominance of UV-C- and UV-Bdissipating pigments in protocells, among them LUCA, and included the split of the line of the LUCA into Bacteria and Archaea and the early branching of the protocyanobacterial line within Bacteria.

From 3.2 to $2.7 \mathrm{Ga}$, a thick upper atmosphere organic haze probably existed due to the rise of the methanogens, bringing the $\mathrm{CH}_{4} / \mathrm{CO}_{2}$ ratio close to 1 , which is the condition for haze production (Lowe and Tice, 2004). The wavelength dependence of the resulting albedo would depend on the size of the agglomerates formed in the atmosphere, probably increasing that of longer wavelengths by a relatively

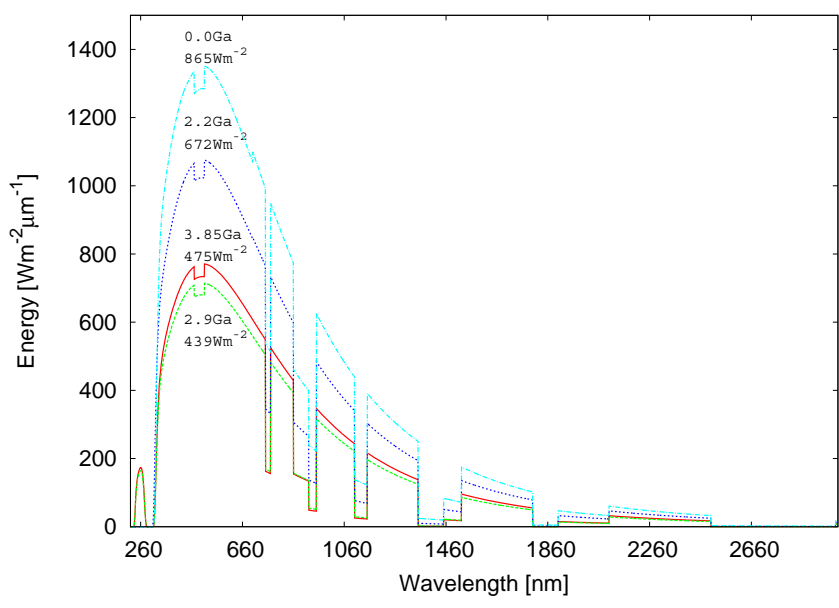

Figure 2. Calculated solar spectra at Earth's surface at particular dates since present assuming the standard solar evolutionary model and using the best available data for the atmospheric gasses, their densities, and surface temperature. The total integrated (over all wavelengths) energy flows midday at the Equator are given below the dates.

greater amount (as on Titan today; McGrath et al., 1998), but would have generally increased the albedo at all wavelengths with an ensuing cooling of Earth's surface locally to glacier temperatures. The biosphere saw the branching of oxygenic cyanobacteria within the protocyanobacterial line and the beginning of gradual $\mathrm{O}_{2}$ accumulation with the continuing dominance of UV-dissipating pigments but the visible pigments rising in importance.

From about 2.7 to $2.45 \mathrm{Ga}$ the organic haze produced by UV-C light on $\mathrm{CH}_{4}$ in the upper atmosphere began to decline as erosion of the continents and tectonic recycling of $\mathrm{CO}_{2}$ reduced the $\mathrm{CH}_{4} / \mathrm{CO}_{2}$ ratio, thereby increasing the intensity of the spectrum at Earth's surface between 320 and $700 \mathrm{~nm}$ while at the same time ozone, resulting from oxygenic photosynthesis, was beginning to reduce the intensity of the UV spectrum between 230 and $290 \mathrm{~nm}$. Dissipation in this wavelength range was now becoming ever more relegated to life-derived ozone in the upper atmosphere. The biosphere was seeing the diversification of cyanobacteria and the appearance of multicellular forms of cyanobacteria, increasingly dissipating in the visible.

After about $2.45-2.2 \mathrm{Ga}$, ozone from oxygenic photosynthesis would have reduced light within the $230-290 \mathrm{~nm}$ wavelength range to less than perhaps a few percent of its value at the beginnings of life $\left(5.5 \pm 2 \mathrm{Wm}^{-2}\right.$ at $\left.3.85 \mathrm{Ga}\right)$. The biosphere was experiencing the endosymbiosis of mitochondria and chloroplasts and the emergence of eukaryotes. Visible-dissipating pigments probably became dominant in this era.

The calculation of the evolution of the solar spectrum at Earth's surface is depicted in Figs. 2 and 3, where at $3.85 \mathrm{Ga}$ we have included the absorption of $\mathrm{H}_{2} \mathrm{~S}$ and aldehydes, 


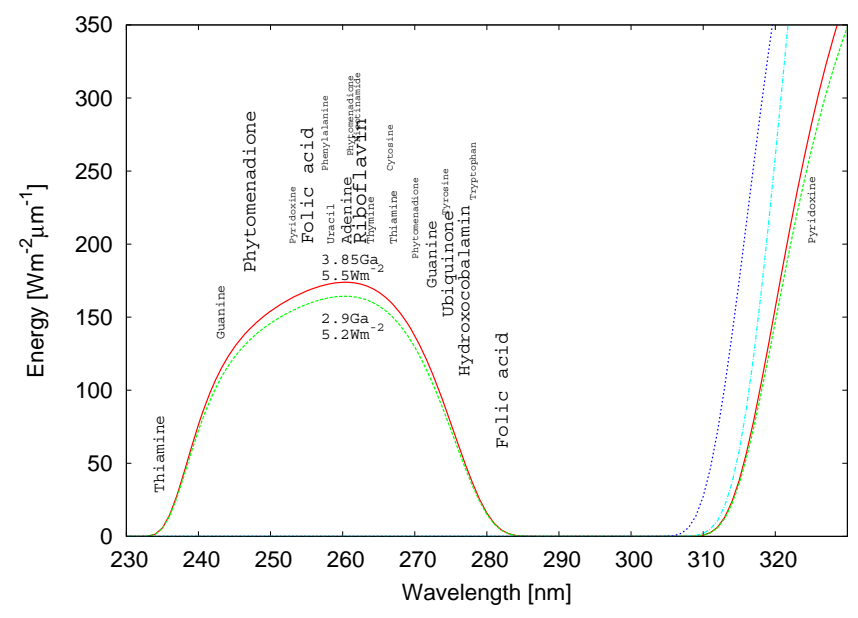

Figure 3. The wavelengths of maximum absorption of many of the fundamental molecules of life (common to all three domains) coincide with the predicted solar spectrum at Earth's surface in the $\mathrm{UV}-\mathrm{C}$ at the time of the origin of life at $3.85 \mathrm{Ga}$ and until at least $2.7 \mathrm{Ga}$. The font size of the letter roughly indicates the relative size of the absorption cross section of the indicated pigment.

Rayleigh scattering for atmospheric pressures at an estimated 1.5 times present-day values, and water at roughly twice its average concentration of present-day values of $5 \mathrm{~mm}$ of precipitable water (Gates, 1980).

The calculated spectrum at $2.9 \mathrm{Ga}$ includes absorption of $\mathrm{H}_{2} \mathrm{~S}$ and aldehydes, Rayleigh scattering for atmospheric pressures at about 1.2 times present-day values, and water at roughly 1.5 times its average present concentration, plus wavelength-independent scattering due to organic haze increasing the bond albedo to 0.6 .

At $2.2 \mathrm{Ga}$ we include absorption due to oxygen at 0.15 times its present-day mass concentration of $21 \%$, giving an absolute value of $3.2 \%$, and ozone also at 0.15 times present-day concentrations, Rayleigh scattering for atmospheric pressure at 1.2 times present-day values, water at 1.2 times its average present-day concentration, and scattering due to organic haze at about $10 \%$ of its late Archean concentration.

For the spectrum calculation at present day, $0.0 \mathrm{Ga}$, we include absorption of oxygen at $21 \%$ concentration, ozone absorption, and Rayleigh scattering at present atmospheric pressures, giving an integrated energy flow of $865 \mathrm{Wm}^{-2}$ midday at the Equator, consistent with measured values (Gates, 1980).

The calculations presented in Figs. 2 and 3 have internal consistency with an increase of about $27 \%$ in the integrated energy flow arriving at the top of Earth's atmosphere since the beginnings of life, and a total of $865 \mathrm{Wm}^{-2}$ arriving at Earth's surface with $9 \%$ of the energy flow in the UV below $400 \mathrm{~nm}$ today. Results for the beginning of life $(\sim 3.85 \mathrm{Ga})$ are $5.5 \mathrm{Wm}^{-2}$ within the $230-290 \mathrm{~nm}$ region arriving at Earth's surface and $4.3 \mathrm{Wm}^{-2}$ within the reduced wavelength $240-270 \mathrm{~nm}$ region, roughly consistent with Sagan's (1973) calculation of $3.3 \mathrm{Wm}^{-2}$.

Figure 3 plots the fundamental molecules of life (primordial organic pigments) which are common to all three domains of life (see Table 1) at their absorption maxima. All pigments absorb and dissipate strongly in the $230-290 \mathrm{~nm}$ range, just where a window existed in Earth's Archean atmosphere. The wavelength range of absorption for each pigment is in fact much wider than can be depicted in the figure, and the asymmetry around peak absorption in most cases is also substantial. For example, guanine actually absorbs strongly over the $240-280 \mathrm{~nm}$ region but has peak absorption at $272.75 \mathrm{~nm}$.

The correlation between the absorption spectra of the fundamental molecules of life and the UV-C solar spectrum at Earth's surface during the Archean presented in Fig. 3 is very supportive of our conjecture that these molecules were among the earliest pigments that arose and evolved as a response to thermodynamic imperative of dissipating the prevailing solar spectrum at Earth's surface. It also lends support to the thermodynamic dissipation theory of the origin of life (Michaelian, 2009, 2011), which suggests that life arose as a response to the thermodynamic imperative of dissipating the prevailing solar photon flux and would have begun by forming pigments at the shorter wavelengths, not only because these are the most photochemically active wavelengths but also because this is the region of greatest possible entropy production per unit photon dissipated, or per unit energy, upon conversion to a black-body spectrum at the temperature of Earth's surface.

In Fig. 4 we provide a timeline showing the time correlation of the prevailing surface solar spectrum with the appearance and dispersal of organic pigments and with important biophysical Earth events.

\section{Discussion and conclusions}

Given the current understanding of the evolution of solarlike stars and a likely, but less certain, evolution of Earth's atmosphere, we have determined the probable history of the solar spectrum at Earth's surface. The most notable feature of this analysis is the existence, since before the beginnings of life at $3.85 \mathrm{Ga}$ and until at least $2.7 \mathrm{Ga}$, of a region of UV light between 230 and $290 \mathrm{~nm}$ of $5.5 \pm 2 \mathrm{Wm}^{-2}$ integrated flux. There is some direct empirical evidence for this UV atmospheric window in the form of ${ }^{33} \mathrm{~S}$ isotope inclusions in diamonds dated at $2.9 \mathrm{Ga}$ that could only have been formed through specific atmospheric photochemical reactions with UV light in this wavelength region (Farquhar et al., 2001). This light could have provided the free energy for a number of photochemical reactions, leading to complex organic pigments which are known today as the "fundamental molecules of life", including RNA, DNA, aromatic amino acids, organic cofactors, quinones, and porphyrins. 


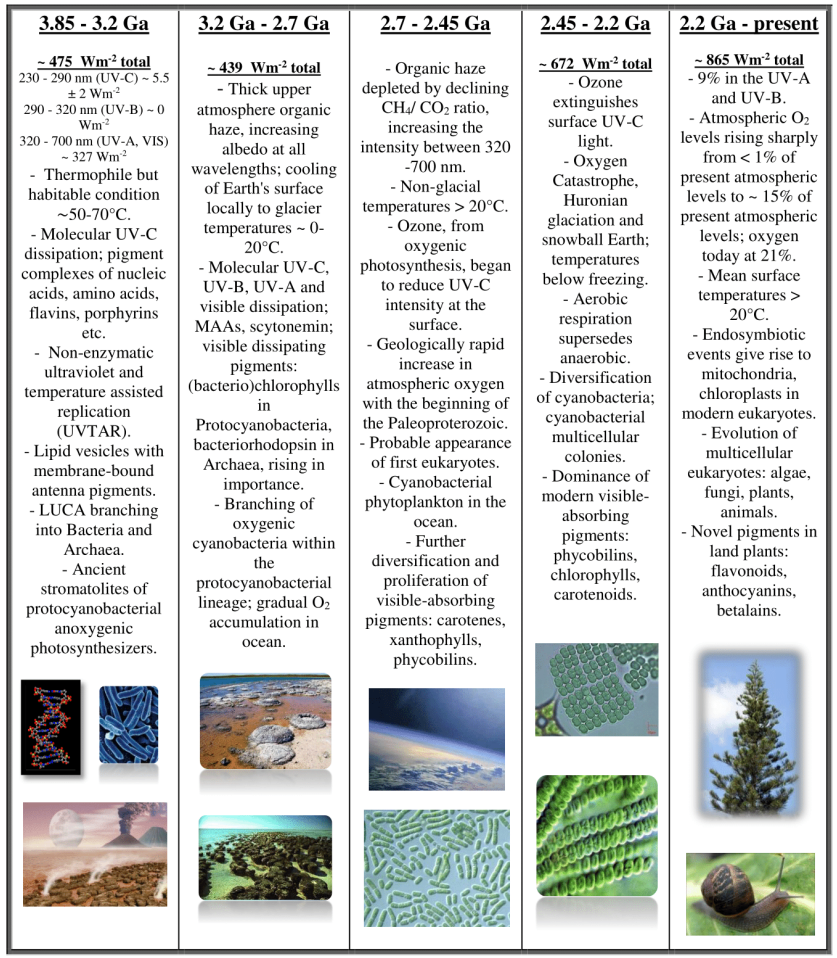

Figure 4. Timeline demonstrating the correlation between the prevailing surface solar spectrum and the appearance and distribution of organic pigments. Major milestones in the evolution of life are also noted in the figure.

These fundamental biomolecules, common to all three domains of life, absorb and dissipate strongly within the UV-C and the higher energy part of the UV-B region, from 230 to $290 \mathrm{~nm}$, especially when intercalated or coupled externally to RNA and DNA which could have acted as rapid quencher molecules. A nonlinear, non-equilibrium thermodynamic directive suggests a spontaneous proliferation of these dissipating molecules, to concentrations much greater than their expected near-equilibrium concentration, over the entire surface of the Earth exposed to this radiation. The proliferation of these molecules to high concentrations and their global dispersion can be explained by the fact that the photochemical production of these pigments is an autocatalytic reaction process established to dissipate the solar photon potential (Michaelian, 2013).

The proliferation and evolution of these pigment molecules over time, which succinctly characterizes all biological and even coupled biotic-abiotic evolution (Michaelian, 2012b), can best be described through five basic tendencies: to increase the ratio of their effective photon absorption cross sections to their physical size, to decrease their electronic excited state lifetimes, to quench radiative deexcitation channels (e.g., fluorescence), to cover ever more completely the prevailing solar spectrum, and finally to disperse over an ever greater surface area of Earth. The appear- ance of mobile protists and animals can be seen as fomenting this thermodynamic directive by providing the vehicle of dispersion and recycling of nutrients with the overall objective of increasing pigment dispersion and thus the global entropy production of Earth in its solar environment.

These fundamental molecules today, having lost their direct dissipating utility, have taken on new roles and are now produced only with the aid of complex enzymes and biosynthetic reaction pathways; however, they are still completely relevant in their supportive role that they play in fomenting the proliferation and dispersion over Earth's surface of the contemporary dissipating pigments in the visible and near UV.

The evidence presented here supports the thermodynamic dissipation theory of the origin of life (Michaelian, 2009, 2011), which states that life arose and proliferated to carry out the thermodynamic function of dissipating the entropically most important part of the solar spectrum (the shortestwavelength photons) prevailing at Earth's surface and that this irreversible process began to evolve and couple with other irreversible abiotic processes, such as the water cycle, to become more efficient, to cover ever more completely the electromagnetic spectrum, and to cover ever more of Earth's surface. This dissipation continues today as the most important thermodynamic function performed by living organisms as part of a greater dissipating system known as "the biosphere" (Michaelian, 2012b).

The revelation of strong and complex interactions of living organisms with their physical environment discovered by Lovelock and collaborators while working on the Gaia theory (Lovelock, 2005) led them to suggest that the entire Earth was one great living organism capable of the autoregulation of its physical attributes, such as the global temperature, the amount of salinity in the oceans, and the oxygen content of the atmosphere, among other characteristics. This auto-regulation was claimed to occur in order to increase the suitability of the Earth environment for life. It is now generally accepted that, although Lovelock's Gaia may be more metaphoric than originally conceived, there is no question that the strong interaction between the biotic and the abiotic, as exposed in the theory of Gaia, is an accurate description of nature.

This strong interaction between the biotic and abiotic is exactly what is expected from a thermodynamic perspective and we would simply call it a "coupling of irreversible processes". Onsager (1931) showed that this would happen as long as the entropy production of the coupled system increases as a result. There are many mundane examples of this type of coupling in the non-equilibrium thermodynamic literature such as the Seebeck effect, in which an electrical current couples to a heat flow. We have maintained that photon dissipation in the pigments which are surrounded by water inside a leaf (or cyanobacteria) couples strongly to the water cycle (Michaelian, 2012a). Together, the system as a whole, pigments in land plants plus water cycle, is much more effi- 
cient at dissipating the solar photon flux than it would be if the two processes acted independently (e.g., pigments confined to the oceans and evapotranspiration reduced to evaporation). The one great "living" organism of Gaia could therefore be identified with the great non-equilibrium dissipative structure, involving the coupling of both biotic and abiotic processes, known as the biosphere. The biosphere is "living" off, and evolving towards greater, solar photon dissipation, as Boltzmann first understood many years ago.

However, and this is where our view differs from that of Gaia, it is entropy production through photon dissipation which is the prima causa of nature, not life. Although life may be locally stabilized through the positive feedbacks delineated in Gaia theory, if other largely abiotic processes are competitive at producing dissipation, given the prevailing physical conditions at Earth's surface and atmosphere, then nature will forsake life, or a great portion of life, for these other processes. This seems to have occurred during global glaciations (snowball Earth events) where pigments and life became severely limited geographically. During these global glaciations, photon dissipation seems to have been relegated to shorter wavelengths (where ice absorbs rather strongly) through sublimation on ice instead of evapotranspiration, and to photon scattering at longer visible wavelengths, which also produces entropy (see Michaelian, 2012a, for the cloud case of Venus as an example). This predominantly abiotic dissipation is also what apparently seems to be occurring today on the rest of the planets in our solar system, perhaps involving pigments (e.g., those discovered in the atmosphere of Venus), to perform the initial photon dissipation, coupled to an "abiotic" irreversible process (e.g., the giant southern vortex on Venus; ESA, 2006). This parallels very closely the irreversible coupling on Earth of organic pigment dissipation with the water cycle.

Lotka (1922) saw the evolution of the biosphere in the opportunity for the origin of a new species which could latch on to a new channel of free energy, the available energy for which all life competes, and that this would therefore allow ecosystems to grow and become more adequate for sustaining life. One could say that this observation was, in some way, an "energetic" precursor to the theory of Gaia in which organisms coevolve together and with their abiotic environment to increase the suitability of Earth for themselves and all life in general. Our suggestion presented here is that these new channels for latching on to free energy most often become available through the evolution of new, more efficient, organic pigments which cover, over evolutionary time, ever more completely the solar spectrum, as well as the evolution of their associated organismic vehicles which allow the pigments to spread into inhospitable regions of Earth's surface. This happens not for making Earth more suitable to life but for the greater thermodynamic role of increasing the solar photon dissipation rate of the biosphere.

In our view, there can be no inherent "interest" in selfpreservation assigned to life; rather it must be viewed as a dissipative structure (process) which surges and wanes in response to the impressed solar photon potential and to secondary impressed chemical potentials derived from it. Other routes to this entropy production that are traditionally considered as being more abiotic are also available (such as Earth's water cycle or the giant southern vortex on Venus), and which route, or coupling of routes, nature takes will depend strongly on initial conditions and subsequent perturbation, but will be guided by the principle (probabilistic) of increasing the global entropy production of Earth in its solar environment (Michaelian, 2012a).

Our conjecture provides a new avenue for exploration of Earth's ancient atmosphere based on pigment history analysis. For example, the lack of primordial pigments absorbing between 290 and $320 \mathrm{~nm}$ strongly suggests the presence of aldehydes in the Archean atmosphere as postulated by Sagan (1973). Finally, our conjecture sheds new light on the origin of photosynthesis. The demonstrated abiotic production of porphyrins using UV light and their UV-C and UV$\mathrm{B}$ absorption and dissipation characteristics when stacked as aggregates and intercalated or coupled externally to RNA or DNA suggests that photosynthesis arose as an adjunct to the porphyrins UV light-harvesting and dissipation function, as postulated by Mulkidjanian and Junge (1997), when the photochemically active light at Earth's surface began to wane as life-derived ozone took on the dissipative role at these wavelengths in the upper atmosphere. Photosynthetic proliferation at visible wavelengths then superseded UV-C dissipative autocatalytic proliferation. A greater in-depth analysis remains to be performed on the relation between RNA/DNA and many of the fundamental pigment molecules of life, including the amino acids and the porphyrins, and on the relation between dissipation and photosynthesis. We are presently engaged in analysis and experiments to explore these relations in greater detail.

Acknowledgements. The authors are grateful to K. Hulsman, F. Veroustraete, M. Vitas, A. Zotin, and an anonymous referee for suggestions on improving the manuscript. K. Michaelian is grateful for the financial support provided by DGAPA-UNAM project number IN-103113.

Edited by: K. Fennel

\section{References}

Abo-Riziq, A., Grace, L., Nir, E., Kabelac, M., Hobza, P., and de Vries, M. S.: Photochemical selectivity in guanine-cytosine base-pair structures, Proc. Natl. Acad. Sci., 102, 20-23, 2005.

Agati, G., Matteini, P., Goti, A., and Tattini, M.: Chloroplast-located flavonoids can scavenge singlet oxygen, New Phytol., 174, 7789, 2007.

Ajlani, G. and Vernotte, C.: Construction and characterization of a phycobiliprotein-less mutant of Synechocystis sp. PCC 6803, Plant Mol. Biol., 37, 577-580, 1998. 
Allen, J. F. and Martin, W.: Evolutionary biology - out of thin air, Nature, 445, 610-612, 2007.

Altermann, W. and Kazmierczak, J.: Archean microfossils: a reappraisal of early life on Earth, Res. Microbiol., 154, 611-617, 2003.

Amard, B. and Bertrand-Sarfati, J.: Microfossils in 2000Ma old cherty stromatolites of the Franceville group, Gabon, Precambrian Res., 81, 197-221, 1997.

Anbar, A. D. and Knoll, A. H.: Proterozoic ocean chemistry and evolution: a bioinorganic bridge?, Science, 297, 1137-1142, 2002

Austin, S. M. and Waddell, T. G.: Prebiotic synthesis of vitamin B6-type compounds, Origins Life Evol. B., 29, 287-296, 1999.

Bahcall, J. N., Pinsonneault, M. H., and Basu, S.: Solar models: current epoch and time dependences, neutrinos, and helioseismological properties, Astrophys. J., 555, 990-1012, 2001.

Ball, S., Colleoni, C., Cenci, U., Raj, J. N., and Tirtiaux, C.: The evolution of glycogen and starch metabolism in eukaryotes gives molecular clues to understand the establishment of plastid endosymbiosis, J. Exp. Bot., 62, 1775-1801, 2011.

Balskus, E. P., Case, R. J., and Walsh, C. T.: The biosynthesis of cyanobacterial sunscreen scytonemin in intertidal microbial mat communities, FEMS Microbiol Ecol., 77, 322-332, 2011.

Baudouin-Cornu, P. and Thomas, D.: Evolutionary biology: oxygen at life's boundaries, Nature, 445, 35-36, 2007.

Beale, S. I.: Biosynthesis of phycobilins, Chem. Rev., 93, 785-802, 1993.

Bekker, A., Holland, H. D., Wang, P. L., Rumble III, D., Stein, H. J., Hannah, J. L., Coetzee, L. L., and Beukes, N. J.: Dating the rise of atmospheric oxygen, Nature, 427, 117-120, 2004.

Bengtson, S., Belivanova, V., Rasmussen, B., and Whitehouse, M.: The controversial "Cambrian" fossils of the Vindhyan are real but more than a billion years older, P. Natl. Acad. Sci. USA, 106, 7729-7734, 2009.

Bernstein, M. P., Sandford, S. A., Allamandola, L. J., Gillette, J. S., Clemett, S. J., and Zare, R. N.: UV irradiation of polycyclic aromatic hydrocarbons in ices: production of alcohols, quinones, and ethers, Science, 283, 1135-1138, 1999.

Brautigam, C. A., Smith, B. S., Ma, Z., Palnitkar, M., Tomchick, D. R., Machius, M., and Deisenhofer, J.: Structure of the photolyase-like domain of cryptochrome 1 from Arabidopsis thaliana, P. Natl. Acad. Sci. USA, 101, 12142-12147, 2004.

Brocks, J. J., Logan, G. A., Buick, R., and Summons, R. E.: Archean molecular fossils and the early rise of eukaryotes, Science, 285, 1033-1036, 1999.

Brocks, J. J., Buick, R., Logan, G. A., and Summons, R. E.: Composition and syngeneity of molecular fossils from the 2.78 to 2.45 billion-year-old Mount Bruce Supergroup, Pilbara Craton, Western Australia, Geochim. Cosmochim. Ac., 67, 4289-4319, 2003.

Brown, S. B., Houghton, J. D., and Vernon, D. I.: Biosynthesis of phycobilins. Formation of the chromophore of phytochrome, phycocyanin and phycoerythrin, J. Photoch. Photobio. B, 5, 323, 1990.

Bryant, D. A. and Frigaard, N. U.: Prokaryotic photosynthesis and phototrophy illuminated, Trends Microbiol., 14, 488-496, 2006.

Butterfield, N. J.: Bangiomorpha pubescens n. gen., n. sp.: implications for the evolution of sex, multicellularity, and the Mesoproterozoic/Neoproterozoic radiation of eukaryotes, Paleobiology, 263, 386-404, 2000.
Caetano-Anollés, G., Kim, K. M., and Caetano-Anollés, D.: The phylogenomic roots of modern biochemistry: origins of proteins, cofactors and protein biosynthesis, J. Mol. Evol., 74, 1-34, 2012.

Callahan, M. P., Smith, K. E., Cleaves, H. J., Ruzica, J., Stern, J. C., Glavin, D. P., House, C. H., and Dworkin, J. P: Carbonaceous meteorites contain a wide range of extraterrestrial nucleobases, P. Natl. Acad. Sci. USA, 108, 13995-13998, 2011.

Callis, P. R.: Polarized fluorescence and estimated lifetimes of the DNA bases at room temperature, Chem. Phys. Lett., 61, 563567, 1979.

Canfield, D. E.: The early history of atmospheric oxygen: homage to Robert M. Garrels, Annu. Rev. Earth Pl. Sc., 33, 1-36, 2005.

Canfield, D. E. and Teske, A.: Late Proterozoic rise in atmospheric oxygen concentration inferred from phylogenetic and sulphurisotope studies, Nature, 382, 127-132, 1996.

Castenholz, R. W. and Garcia-Pichel, F.: Cyanobacterial Responses to UV-Radiation, in: The Ecology of Cyanobacteria, edited by: Whitton, B. A. and Potts, M., Kluwer Academic Publishers, Dordrecht, the Netherlands, 591-611, 2002.

Caughey, W. S., Smythe, G. A., O'Keeffe, D. H., Maskasky, J. E., and Smith M. I.: Heme A of cytochrome c oxicase. Structure and properties: comparisons with hemes $\mathrm{B}, \mathrm{C}$, and $\mathrm{S}$ and derivatives, J. Biol. Chem., 250, 7602-7622, 1975.

Cavalier-Smith, T.: Membrane heredity and early chloroplast evolution, Trends Plant Sci., 5, 174-182, 2000.

Christie, J. M., Arvai, A. S., Baxter, K. J., Heilmann, M., Pratt, A. J., O’Hara, A., Kelly, S. M., Hothorn, M., Smith, B. O., Hitomi, K., Jenkins, G. I., and Getzoff, E. D.: Plant UVR8 photoreceptor senses UV-B by tryptophan-mediated disruption of cross-dimer salt bridges, Science, 335, 1492-1496, 2012.

Cleaves, H. and Miller, S.: The nicotinamide biosynthetic pathway is a by-product of the RNA World, J. Mol. Evol., 52, 73-77, 2001.

Cleaves, H. J., Chalmers, J. H., Lazcano, A., Miller, S. L., and Bada, J. L.: A reassessment of prebiotic organic synthesis in neutral planetary atmospheres, Origins Life Evol. B., 38, 105-115, 2008.

Clarke, J. T., Warnock, R. C. M., and Donoghue, P. C. J.: Establishing a time-scale for plant evolution, New Phytol., 192, 266-301, 2011.

Cnossen, I., Sanz-Forcada, J., Favata, F., Witasse, O., Zegers, T., and Arnold, N. F.: The habitat of early life: solar X-ray and UV radiation at Earth's surface 4-3.5 billion years ago, J. Geophys. Res., 112, E02008, doi:10.1029/2006JE002784, 2007.

Crespo-Hernández, C. E., Cohen, B., Hare, P. M., and Kohler, B.: Ultrafast excited-state dynamics in nucleic acids, Chem. Rev., 104, 1977-2019, 2004.

Crounse, J., Sistrom, W. R., and Nemser, S.: Carotenoid pigments and the in vivo spectrum of bacteriochlorophyll, Photochem. Photobiol., 2, 361-375, 1963.

Crowe, S. A., Døssing, L. N., Beukes, N. J., Bau, M., Stephanus, J., Kruger, J., Frei, R., and Canfield, D. E.: Atmospheric oxygenation three billion years ago, Nature, 501, 535-538, 2013.

Crowell, J. C.: Pre-Mesozoic ice ages; their bearing on understanding the climate system, Mem. Geol. Soc. Amer., 192, 1-106, 1999.

DasSarma, S.: Extreme halophiles are models for astrobiology, Microbe, 1, 120-127, 2006.

DasSarma, S.: Extreme microbes, Am. Sci., 95, 224-231, 2007. 
Delwiche, C. W.: Tracing the thread of plastid diversity through the tapestry of life. Am. Nat., 154, S164-S177, 1999.

Dixon, J. M., Taniguchi, M., and Lindsey, J. S.: PhotochemCAD 2. A refined program with accompanying spectral databases for photochemical calculations, Photochem. Photobiol., 81, 212213, 2005 .

Domagal-Goldman, S. D., Kasting, J. F., Johnston, D. T., and Farquhar, J.: Organic haze, glaciations and multiple sulfur isotopes in the Mid-Archean Era, Earth Planet. Sc. Lett., 269, 29-40, 2008.

Doolittle, W. F.: Uprooting the tree of life, Sci. Am., 282, 90-95, 2000.

Dorren, J. D. and Guinan, E. F.: The Sun in time: detecting and modeling magnetic inhomogenities on solar-type stars, in: The Sun as a Variable Star, edited by: Pap, J. M., Frölich, C., Hudson, H. S., and Solanki, S. K., Cambridge University Press, Cambridge, 206-216, 1994.

Doughty, C. E., Wolf, A., and Malhi, Y.: The legacy of the Pleistocene megafauna extinctions on nutrient availability in Amazonia, Nat. Geosci., 6, 761-764, doi:10.1038/ngeo1895, 2013.

Dowler, M. J., Fuller, W. D., Orgel, L. E., and Sanchez, R. A.: Prebiotic synthesis of propiolaldehyde and nicotinamide, Science, 169, 1320-1321, 1970.

Du, H., Fuh, R.-C. A., Li, J., Corkan, L. A., and Lindsey, J. S.: PhotochemCAD: a computeraided design and research tool in photochemistry, Photochem. Photobiol., 68, 141-142, 1998.

Edelhoch, H.: Spectroscopic determination of tryptophan and tyrosine in proteins, Biochemistry-US, 6, 1948-1954, 1967.

El Albani, A., Bengtson, S., Canfield, D. E., Bekker, A., Macchiarelli, R., Mazurier, A., Hammarlund, E., Boulvais, P., Dupuy, J.-J., Fontaine, C., Fuersich, F. T., Gauthier-Lafaye, F., Janvier, P., Javaux, E., Ossa, F., Pierson-Wickmann, A.-C., Riboulleau, A., Sardini, P., Vachard, D., Whitehouse, M., and Meunier, A.: Large colonial organisms with coordinated growth in oxygenated environments 2.1 Gyr ago, Nature, 466, 100-104, 2010.

Emelyanov, V. V.: Rickettsiaceae, rickettsia-like endosymbionts, and the origin of mitocondria, Bioscience Rep., 21, 1-17, 2001.

Erwin, D. and Valentine, J.: The Cambrian Explosion: The Construction of Animal Biodiversity, 1st edn., Roberts and Company Publishers, 2013.

ESA: European Space Agency ,June 27, Double vortex at Venus south pole unveiled, ScienceDaily Retrieved August 15, 2015, available at: http://www.sciencedaily.com/releases/2006/ 06/060627104232.htm, 2006.

Evreinova, T. N., Mamontova, T. W., Karnauhov, V. N., Stephanov, S. B., and Hrust, U. R.: Coacervate systems and origin of life, Origins of life, 5, 201-205, 1974.

Falkowski, P. G. and Isozaki, Y.: Geology. The story of $\mathrm{O}_{2}$, Science, 322, 540-542, 2008.

Falkowski, P. G., Katz, M. E., Knoll, A. H., Quigg, A., Raven, J. A., Schofield, O., and Taylor, F. J.: The evolution of modern eukaryotic phytoplankton, Science, 305, 354-360, 2004.

Farquhar, J., Savarino, J., Airieau, S., and Thiemens, M. H.: Observation of wavelength sensitive mass-independent sulfur isotope effects during $\mathrm{SO}_{2}$ photolysis: implications for the early atmosphere, J. Geophys. Res., 106, 32829-32839, 2001.

Fasman, G. D.: Nucleic acids, in: Handbook of Biochemistry and Molecular Biology, Vol. I, 3rd edn., CRC Press, Cleveland, Ohio, 65-215, 1975.
Fasman, G. D.: Proteins, in: Handbook of Biochemistry and Molecular Biology, Vol. I, 3rd edn., CRC Press, Cleveland, Ohio, 183203, 1976.

Feng, D. F., Cho, G., and Doolittle, R. F.: Determining divergence times with a protein clock: update and reevaluation, P. Natl. Acad. Sci. USA, 94, 13028-13033, 1997.

Ferroni, L., Klisch, M., Pancaldi, S., and Häder, D.-P.: Complementary UV-absorption of mycosporine-like amino acids and scytonemin is responsible for the UV-insensitivity of photosynthesis in Nostoc flagelliforme, Mar. Drugs, 8, 106-121, 2010.

Fox, S. W. and Harada, K.: Thermal copolymerization of amino acids to a product resembling protein, Science, 128, 1214, doi:10.1126/science.128.3333.1214, 1958.

Fugate, R. D., Chin, C.-A., and Song, P.-S.: A spectroscopic analysis of vitamin B12 derivatives, Biochim. Biophys. Acta, 421, 1-11, 1976.

Garcia-Pichel, F.: Solar ultraviolet and the evolutionary history of cyanobacteria, Origins Life Evol. B., 28, 321-347, 1998.

Georgopapadakou, N. H. and Scott, A. I.: On B12 biosynthesis and evolution, J. Theor. Biol., 69, 381-384, 1977.

Gerakines, P. A., Moore, M. H., and Hudson, R. L.: Ultraviolet photolysis and proton irradiation of astrophysical ice analogs containing hydrogen cyanide, Icarus, 170, 202-213, 2004.

Glansdorff, N., Xu, Y., and Labedan, B.: The Last Universal Common Ancestor: emergence, constitution and genetic legacy of an elusive forerunner, Biol. Direct., 3, 29, doi:10.1186/1745-61503-29, 2008.

Glick, D.: Methods of Biochemical Analysis, Interscience Publishers Inc. MET, New York, 199-200, 1964.

Goldfarb, A. R., Saidel, L. J., and Mosovich, E.: The ultraviolet absorption spectra of proteins, J. Biol. Chem., 193, 397-404, 1951.

Golubic, S. and Lee, S. J.: Early cyanobacterial fossil record: preservation, palaeoenvironments and identification, Eur. J. Phycol., 34, 339-348, 1999.

Gomes, R., Levison, H. F., Tsiganis, K., and Morbidelli, A.: Origin of the cataclysmic Late Heavy Bombardment period of the terrestrial planets, Nature, 435, 466-469, 2005.

Gould, K. S. and Lister, C.: Flavonoid functions in plants, in: Flavonoids: Chemistry, Biochemistry and Applications, edited by: Andersen, Ø. M. and Markham, K. R., CRC Press LLC, CRC Press, Taylor \& Francis Group, 6000 Broken Sound Parkway NW, 397-441, 2006.

Grassineau, N. V., Nisbet, E. G., Bickle, M. J., Fowler, C. M., Lowry, D., Mattey, D. P., Abell, P., and Martin, A.: Antiquity of the biological sulphur cycle: evidence from sulphur and carbon isotopes in 2700 million-year-old rocks of the Belingwe Belt, Zimbabwe, P. Roy. Soc. Lon. B Bio., 268, 113-119, 2001.

Gustavsson, T., Bányász, A., Lazzarotto, E., Markovitsi, D., Scalmani, G., Frisch, M. J., Barone, V., and Improta, R.: Singlet excited-state behavior of uracil and thymine in aqueous solution: a combined experimental and computational study of 11 uracil derivatives, J. Am. Chem. Soc., 128, 607-619, 2006.

Guzik, J. A., Willson, L. A., and Brunish, W. M.: A comparison between mass-losing and standard solar models, Ap. J., 319, 957965, 1987.

Hatier, J.-H. B. and Gould, K. S.: Anthocyanin function in vegetative organs, in: Anthocyanins: Biosynthesis, Functions, and Applications, edited by: Gould, K., Davies, K. M., and Winefield, 
C., Springer, Springer Science + Business Media LLC, Spring Street New York, NY, 1-12, 2009.

Havaux, M., Guedeney, G., He, Q., and Grossman, A. R.: Elimination of high-light-inducible polypeptides related to eukaryotic chlorophyll a/b-binding proteins results in aberrant photoacclimation in Synechocystis PCC6803, Biochim. Biophys. Acta, 1557, 21-33, 2003.

Heckman, D. S., Geiser, D. M., Eidell, B. R., Stauffer, R. L., Kardos, N. L., and Hedges, S. B.: Molecular evidence for the early colonization of land by fungi and plants, Science, 293, 1129-1133, 2001.

Heinz, B. and Ried, W.: The formation of chromophores through amino acid thermolysis and their possible role as prebiotic photoreceptors, Biosystems, 14, 33-40, 1981.

Heinz, B. and Ried, W.: The molecular structure of "chromo proteinoids" - amino acid thermolysates containing abiogenetically produced flavins and deazaflavins as prosthetic groups, Origins of life, 14, 279-289, 1984.

Heinz, B., Ried, W., and Dose, K.: Thermal production of pteridines and flavins from amino acid mixtures, Angew. Chem., 91, 510$511,1979$.

Hill, J. A., Pratt, J. M., and Williams, R. J. P.: The chemistry of vitamin B12, Part I, The valency and spectrum of the coenzyme, J. Chem. Soc., 5149-5153, 1964.

Hodgson, G. and Baker, B.: Evidence for porphyrins in the Orgueil meteorite, Nature, 202, 125-131, 1964.

Hodgson, G. and Baker, B.: Porphyrin abiogenesis from pyrrole and formaldehyde under simulated geochemical conditions, Nature, 216, 29-32, 1967.

Hodgson, G. W. and Ponnamperuma, C.: Prebiotic porphyrin genesis: porphyrins from electric discharge in methane, ammonia, and water vapor, P. Natl. Acad. Sci. USA, 59, 22-28, 1968.

Holland, H. D.: The oxygenation of the atmosphere and oceans, Philos. T. Roy. Soc. B, 361, 903-915, 2006.

Holliday, G. L., Thornton, J. M., Marquet, A., Smith, A. G., Rébeillé, F., Mendel, R., Schubert, H. L., Lawrence, A. D., and Warren, M. J.: Evolution of enzymes and pathways for the biosynthesis of cofactors, Nat. Prod. Rep., 24, 972-987, 2007.

Jahn, D., Moser, J., Schubert, W.-D., and Heinz, D. W.: Transfer RNA-dependent aminolevulinic acid formation: structure and function of glutamyl-tRNA synthetase, reductase and glutamate1-semialdehyde-2,1-aminomutase, in: Chlorophylls and Bacteriochlorophylls: Biochemistry, Biophysics, Functions and Applications, edited by: Grimm, B., Porra, R. J., Rüdiger, W., and Scheer, H., Advances in Photosynthesis and Respiration, vol. 25, edited by: Govindjee, A. Springer, Dordrecht, The Netherlands, 159-171, 2006.

Jasechko, S., Sharp, Z. D., Gibson, J. J., Birks, S.. J., Yi, Y., and Fawcett, P. J.: Terrestrial wáter fluxes dominated by transpiration, Nature, 496, 347-350, 2013.

Javaux, E. J., Knoll, A. H., and Walter, M. R.: Morphological and ecological complexity in early eukaryotic ecosystems, Nature, 412, 66-69, 2001.

Johnson, E. W., Briggs, D. E. G., Suthren, R. J., Wright, J. L., and Tunnicliff, S. P.: Freshwater arthropod traces from the subaerial Ordovician Borrowdale Volcanic Group, English Lake District, Geol. Mag., 131, 395-406, 1994.

Johnson, J. E., Webb, S. M., Thomas, K., Ono, S., Kirschvink, J. L., and Fischer, W. W.: Manganese-oxidizing photosynthesis before the rise of cyanobacteria, P. Natl. Acad. Sci. USA, 110, 1123811243, 2013.

Kalisky, O., Feitelson, J., and Ottolenghi, M.: Photochemistry and fluorescence of bacteriorhopsin excited in its 280-nm band, Biochemistry-US, 20, 205-209, 1981.

Karam, P. A.: Inconstant Sun: how solar evolution has affected cosmic and ultraviolet radiation exposure over the history of life on Earth, Health Phys., 84, 322-333, 2003.

Kasting, J. F., Zahnle, K. J., and Walker, J. C. G.: Photochemistry of methane in the Earth's early atmosphere, Precambrian Res., 20, 121-148, 1983.

Keeling, P. J.: Diversity and evolutionary history of plastids and their hosts, Am. J. Bot., 91, 1481-1493, 2004.

Kharecha, P., Kasting, J. F., and Siefert, J. L.: A coupled atmosphere-ecosystem model of the early Archean Earth, Geobiology, 3, 53-76, 2005.

Kiang, N. Y., Siefert, J., Govindjee, A., and Blankenship, R. E.: Spectral signatures of photosynthesis. I. Review of Earth organisms, Astrobiology, 7, 222-251, 2007.

Kim, E. and Archibald, J. M.: Diversity and evolution of plastids and their genomes, in: The Chloroplast-Interactions with the Environment, edited by: Aronsson, H. and Sandelius, A. S., Springer-Verlag, Berlin, 1-40, 2008.

Kleidon, A. and Renner, M.: A simple explanation for the sensitivity of the hydrologic cycle to surface temperature and solar radiation and its implications for global climate change, Earth Syst. Dynam., 4, 455-465, doi:10.5194/esd-4-455-2013, 2013.

Knauth, L. P.: Isotopic signatures and sedimentary records, in: Lecture Notes in Earth Sciences \#43, edited by: Clauer, N. and Chaudhuri, S., Springer-Verlag, Berlin, 123-152, 1992.

Knauth, L. P. and Lowe, D. R.: High Archean climatic temperature inferred from oxygen isotope geochemistry of cherts in the $3.5 \mathrm{Ga}$ Swaziland group, South Africa, Geol. Soc. Am. Bull., 115, 566580, 2003.

Knoll, A. H. and Carroll, S. B.: Early animal evolution: emerging views from comparative biology and geology, Science, 284, 2129-2137, 1999.

Kolesnikov, M. P. and Egorov, I. A.: Porphyrins and phycobilins in Precambrian rocks, Orig. Life, 8, 383-390, 1977.

Kopp, R. E., Kirschvink, J. L., Hilburn, I. A., and Nash, C. Z.: The Paleoproterozoic snowball Earth: a climate disaster triggered by the evolution of oxygenic photosynthesis, P. Natl. Acad. Sci. USA, 102, 11131-11136, 2005.

Koziol, J.: Studies on flavins in organic solvents I. Spectral characteristics of riboflavin, riboflavin tetrabutyrate and lumichrome, Photochem. Photobiol., 5, 41-54, 1966.

Kritsky, M. S., Lyudnikova, T. A., Mironov, E. A., and Moskaleva, I. V.: The UV radiation-driven reduction of pterins in aqueous solution, J. Photoch. Photobio. B, 39, 43-48, 1997.

Kritsky, M. S., Telegina, T. A., Vechtomova, Y. L., Kolesnikov, M. P., Lyudnikova, T. A., and Golub, O. A.: Excited flavin and pterin coenzyme molecules in evolution, Biochemistry-Moscow,+ 75 , 1200-1216, 2010.

Kritsky, M. S., Telegina, T. A., Vechtomova, Y. L., Kolesnikov, M. P., Lyudnikova, T. A., and Buglak, A. A.: Photoexcited molecules of pteridine derivatives in prebiotic and biological evolution, $\mathrm{Pa}-$ leontol. J., 47, 1074-1079, 2013a.

Kritsky, M. S., Telegina, T. A., Vechtomova, Y. L., and Buglak, A. A.: Why flavins are not competitors of chlorophyll in the evolu- 
tion of biological converters of solar energy, Int. J. Mol. Sci., 14, 575-593, 2013b.

Kumar, A. M., Schaub, U., Soll, D., and Ujwal, M. L.: Glutamyltransfer RNA: at the crossroad between chlorophyll and protein biosynthesis, Trends Plant Sci., 1, 371-376, 1996.

Kwok, S.: Organic matter in space: from star dust to the Solar System, Astrophys. Space Sci., 319, 5-21, 2009.

Kyrpides, N. C. and Ouzounis, C. A.: Nucleic acid-binding metabolic enzymes: living fossils of stereochemical interactions?, J. Mol. Evol., 40, 564-569, 1995.

Larkum, A. W. D.: The evolution of chlorophylls, in: Chlorophylls, edited by: Scheer, H., CRC Press, Boston, 367-383, 1991.

Latorre, A., Durban, A., Moya, A., and Pereto, J.: The role of symbiosis in eukaryotic evolution, in: Origins and Evolution of Life An Astrobiological Perspective, edited by: Gargaud, M., LopezGarcia, P., and Martin, H., Cambridge University press, Cambridge UK, 326-339, 2011.

Lavery, T. J., Roudnew, B., Gill, P., Seymour, J., Seuront, L., Johnson, G., Mitchell, J. G., and Smetacek, V.: Iron defecation by sperm whales stimulates carbon export in the Southern Ocean, P. Roy. Soc. B, 277, 3527-3531, 2010.

Lindsey, J. S., Ptaszek, M., and Taniguchi, M.: Simple formation of an abiotic porphyrinogen in aqueous solution, Origins Life Evol. B., 39, 495-515, 2009.

Lotka, A. J.: Contribution to the energetics of evolution, P. Natl. Acad. Sci., 8, 147-151, 1922.

Lovelock, J. E.: Gaia: Medicine for an ailing planet, 2nd Ed., Gaia Books, New York, 2005.

Lowe, D. R. and Tice, M. M.: Geologic evidence for Archean atmospheric and climatic evolution: fluctuating levels of $\mathrm{CO}_{2}, \mathrm{CH}_{4}$, and $\mathrm{O}_{2}$ with an overriding tectonic control, Geology, 32, 493496, 2004.

MacNaughton, R. B., Cole, J. M., Dalrymple, R. W., Braddy, S. J., Briggs, D. E. G., and Lukie, T. D.: First steps on land: arthropod trackways in Cambrian-Ordovician eolian sandstone, southeastern Ontario, Canada, Geology, 30, 391-394, 2002.

Majerfeld, I. and Yarus, M.: A diminutive and specific RNA binding site for L-tryptophan, Nucleic Acids Res., 33, 5482-5493, 2005.

Martin, W. and Mentel, M.: The origin of mitochondria, Nature Education, 3, 58, 2010.

Mayer, R., Toulme, F., Montenay-Garestier, T., and Helene, C.: The role of tyrosine in the association of proteins and nucleic acids. Specific recognition of single-stranded nucleic acids by tyrosinecontaining peptides, J. Biol. Chem., 254, 75-82, 1979.

McFadden, G. I.: Primary and secondary endosymbiosis and the origin of plastids, J. Phycol., 37, 951-959, 2001.

McGrath, M. A., Courtin, R., and Smith, T. E.: The ultraviolet albedo of titan, Icarus, 131, 382-392, 1998.

McLaren, J., Ngo, D. T., and Olivera B. M.: Pyridine nucleotide metabolism in Escherichia coli. III. Biosynthesis from alternative precursors in vivo, J. Biol. Chem., 248, 5144-5159, 1973.

Meierhenrich, U. J., Muñoz Caro, G. M., Schutte, W. A., Thiemann, W. H., Barbier, B., and Brack, A.: Precursors of biological cofactors from ultraviolet irradiation of circumstellar/interstellar ice analogues, Chemistry, 11, 4895-4900, 2005.

Michaelian, K.: Thermodynamic stability of ecosystems, J. Theor. Biol., 237, 323-335, 2005.

Michaelian, K.: Thermodynamic origin of life, http://arxiv.org/abs/ 0907.0042 (last access: 25 July 2015), 2009.
Michaelian, K.: Thermodynamic dissipation theory for the origin of life, Earth Syst. Dynam., 2, 37-51, doi:10.5194/esd-2-37-2011, 2011.

Michaelian, K.: HESS Opinions "Biological catalysis of the hydrological cycle: life's thermodynamic function", Hydrol. Earth Syst. Sci., 16, 2629-2645, doi:10.5194/hess-16-26292012, 2012a.

Michaelian, K.: The biosphere: a thermodynamic imperative, in: The Biosphere, edited by: Ishwaran, N., INTECH, Paris, 51-60, 2012b.

Michaelian, K.: A non-linear irreversible thermodynamic perspective on organic pigment proliferation and biological evolution, J. Phys. Conf. Ser. 475, 012010 doi:10.1088/17426596/475/1/012010, 2013

Michaelian, K. and Manuel, O.: Origin and evolution of life constraints on the solar model, J. Mod. Phys, 2, 587-594, 2011.

Michaelian, K. and Santillán Padilla, N.: DNA Denaturing through UV-C Photon Dissipation: A Possible Route to Archean Nonenzymatic Replication, BioRxiv, Cold Spring Harbor Labs Journals, doi:10.1101/009126, 2014.

Middleton, C. T., de la Harpe, K., Su, C., Law, Y. K., CrespoHernandez, C. E., and Kohler B.: DNA excited - state dynamics: from single bases to the double helix, Annu. Rev. Phys. Chem., 60, 217-239, 2009.

Miller, S. L.: A production of amino acids under possible primitive Earth conditions, Science, 117, 528-529, 1953.

Miller, S. L.: The formation of organic compounds on the primitive earth, Ann. NY Acad. Sci., 69, 260-275, 1957.

Mojzsis, S. J., Harrison, T. M., and Pidgeon, R. T.: Oxygen-isotope evidence from ancient zircons for liquid water at the Earth's surface 4300 Myr ago, Nature, 409, 178-181, 2001.

Montané, M. H. and Kloppstech, K.: The family of light-harvestingrelated proteins (LHCs, ELIPs, HLIPs): was the harvesting of light their primary function?, Gene, 258, 1-8, 2000.

Moon, Y. J., Lee, E. M., Park, Y. M., Park, Y. S., Chung, W. I., and Chung, Y. H.: The role of cyanopterin in UV/blue light signal transduction of cyanobacterium Synechocystis sp. PCC 6803 phototaxis, Plant Cell Physiol., 51, 969-980, 2010.

Mulkidjanian, A. Y. and Galperin, M. Y.: A time to scatter genes and a time to gather them: evolution of photosynthesis genes in bacteria, Adv. Bot. Res., 66, 1-35, 2013.

Mulkidjanian, A. Y. and Junge, W.: On the origin of photosynthesis as inferred from sequence analysis, Photosynth. Res., 51, 27-42, 1997.

Mulkidjanian, A. Y., Cherepanov, D. A., and Galperin, M. Y.: Survival of the fittest before the beginning of life: selection of the first oligonucleotide-like polymers by UV light, BMC Evol. Biol., 3, 12, doi:10.1186/1471-2148-3-12, 2003.

Mulkidjanian, A. Y., Koonin, E. V., Makarova, K. S., Mekhedov, S. L., Sorokin, A., Wolf, Y. I., Dufresne, A., Partensky, F., Burd, H., Kaznadzey, D., Haselkorn, R., and Galperin, M. Y.: The cyanobacterial genome core and the origin of photosynthesis, $\mathrm{P}$. Natl. Acad. Sci. USA, 103, 13126-13131, 2006.

Müller, P., Li, X., and Niyogi, K. K.: Non-photochemical quenching. A response to excess light energy, Plant Physiol., 125, 15581566, 2001.

Nisbet, E. G. and Sleep, N. H.: The habitat and nature of early life, Nature, 409, 1083-1091, 2001. 
Nobel, P. S.: Physicochemical and Environmental Plant Physiology, 4th edn., Academic Press, San Diego, CA, 238-244, 2009.

Noffke, N., Christian, D., Wacey, D., and Hazen, R. M.: Microbially induced sedimentary structures recording an ancient ecosystem in the ca. 3.48 billion-year-old dresser formation, Pilbara, Western Australia, Astrobiology, 13, 1103-1124, 2013.

Nollet, L. M. L.: Fat-soluble vitamins, in: Food Analysis by HPLC, 3rd edn., edited by: Nollet, L. M. L. and Toldra, F., CRC Press, Taylor \& Francis Group, Parkway NW, 292-296, 2012.

Ohtomo, Y., Kakegawa, T., Ishida, A., Nagase, T., and Rosing, M. T.: Evidence for biogenic graphite in early Archaean Isua metasedimentary rocks, Nat. Geosci., 7, 25-28, 2014.

Olson, J. M.: Photosynthesis in the Archean era, Photosynth. Res., 88, 109-117, 2006.

Olson, J. M. and Pierson, B. K.: Evolution of reaction centers in photosynthetic procariots, Int. Rev. Cytol., 108, 209-248, 1987.

Onsager,L.: Reciprocal Relations in Irreversible Processes I, Phys. Rev. 37, 405-426, 1931.

Oro, J. and Kimball, A. P.: Synthesis of purines under possible primitive earth conditions, I. Adenine from hydrogen cyanide, Arch. Biochem. Biophys., 94, 217-227, 1961.

Pace, C. N., Vajdos, F., Fee, L., Grimsley, G., and Gray, T.: How to measure and predict the molar absorption coefficient of a protein, Protein Sci., 4, 2411-2423, 1995.

Pavlov, A. A., Kasting, J. F., Brown, L. L., Rages, K. A., and Freedman, R.: Greenhouse warming by $\mathrm{CH}_{4}$ in the atmosphere of early Earth, J. Geophys. Res., 105, 11981-11990, 2000.

Pasternack, R. F. and Gibbs, E. J.: Porphyrin and metalloporphyrin interactions with nucleic acids, in: Probing of Nucleic Acids by Metal Complexes of Small Molecules, edited by: Sigel, A. and Sigel, H., Metal Ions in Biological Systems, Vol. 33, Marcel Dekker, New York, 367-391, 1996.

Pasternack, R. F., Giannetto, A., Pagano, P., and Gibbs, E. J.: Selfassembly of porphyrins on nucleic acids and polypeptides, J. Am. Chem. Soc., 113, 7799-7800, 1991.

Pasternack, R. F., Bustamante, C., Collings, P. J., Giannetto, A., and Gibbs, E. J.: Porphyrin assemblies on DNA as studied by a resonance light-scattering technique, J. Am. Chem. Soc., 115, 5393 5399, 1993.

Patel, B. H., Percivalle, C., Ritson, D. J., Duffy. C. M., Sutherland, J. D., Common origins of RNA, protein and lipid precursors in a cyanosulfidic protometabolism, Nature Chemistry, 7, 301-307, doi:10.1038/nchem.2202, 2015.

Pecourt, J. L., Peon, J., and Kohler, B.: Ultrafast internal conversion of electronically excited RNA and DNA nucleosides in water, J. Am. Chem. Soc., 122, 9348-9349, 2000.

Pisani, D., Poling, L. L., Lyons-Weiler, M., Hedges, S. B.: The colonization of land by animals: molecular phylogeny and divergence times among arthropods, BMC Biol., 2, 1, doi:10.1186/17417007-2-1, 2004.

Podda, M., Weber, C., Traber, M. G., and Packer, L.: Simultaneous determination of tissue tocopherols, tocotrienols, ubiquinols, and ubiquinones, J. Lipid Res., 37, 893-901, 1996.

Polyansky, A. A. and Zagrovic, B.: Evidence of direct complementary interactions between messenger RNAs and their cognate proteins, Nucleic Acids Res., 41, 8434-8443, 2013.

Poole, A. M. and Penny, D.: Evaluating hypotheses for the origin of eukaryotes, Bioessays, 29, 74-84, 2007.
Portwich, A. and Garcia-Pichel, F.: Biosynthetic pathway of mycosporines (mycosporine-like amino acids) in the cyanobacterium Chlorogloeopsis sp. strain PCC 6912, Phycologia, 42, 384-392, 2003.

Powner, M. W., Gerland, B., and Sutherland, J. D.: Synthesis of activated pyrimidine ribonucleotides in prebiotically plausible conditions, Nature, 459, 239-242, 2009.

Pratt, J. M. and Thorp, R. G.: The chemistry of vitamin B12, Part $\mathrm{V}$, The class (b) character of the cobaltic ion, J. Chem. Soc. A, 187-191, 1966.

Prigogine, I.: Thermodynamics of Irreversible Processes, Wiley, New York, 1967.

Raffaelli, N.: Nicotinamide coenzyme synthesis: a case of ribonucleotide emergence or a byproduct of the RNA world?, in: Origins of Life: The Primal Self-Organization, edited by: Egel, R., Lankenau, D. H., and Mulkidjanian, A. Y., Springer-Verlag, Heidelberg, Germany, 185-208, 2011.

Raven, J. A. and Edwards, D.: Roots: evolutionary origins and biogeochemical significance, J. Exp. Bot., 52, 381-401, 2001.

Raymond, J. and Segre, D.: The effect of oxygen on biochemical networks and the evolution of complex life, Science, 311, 1764 1767, 2006.

Ribas, I., Guinan, E. F., Güdel, M., and Audard, M.: Evolution of the solar activity over time and effects on planetary atmospheres. I. High-energy irradiances (1-1700 Å), Ap. J., 622, 680-694, 2005.

Rowan, K. S.: Photosynthetic Pigments of Algae, Cambridge University Press, Cambridge, 112-210, 1989.

Ruban, A. V.: The photosynthetic membrane: molecular mechanisms and biophysics of light harvesting, John Wiley and Sons, Ltd, Chichester, West Sussex, United Kingdom, 81-91, 2012.

Russell, M. J. and Hall, A. J.: The onset and early evolution of life, in: Evolution of Early Earth's Atmosphere, Hydrosphere, and Biosphere - Constraints from Ore Deposits, edited by: Kesler, S. E. and Ohmoto, H., Geol. Soc. Am., Boulder, CO, 198, 1-32, 2006.

Rye, R. and Holland, H. D.: Paleosols and the evolution of atmospheric oxygen: a critical review, Am. J. Sci., 298, 621-672, 1998.

Sagan, C.: Ultraviolet selection pressure on the earliest organisms, J. Theor. Biol., 39, 195-200, 1973.

Sagan, C. and Chyba, C.: The early faint Sun paradox: organic shielding of ultraviolet-labile greenhouse gases, Science, 276, 1217-1221, 1997.

Sagan, C. and Miller, S. L.: Molecular synthesis in simulated reducing planetary atmospheres, Astron. J. 65, 499-505, 1960.

Schidlowski, M.: A 3800-million-year isotopic record of life from carbon in sedimentary rocks, Nature, 333, 313-318, 1988.

Schidlowski, M.: Carbon isotopes as biogeochemical recorders of life over 3.8 Ga of Earth history: evolution of a concept, Precambrian Res., 106, 117-134, 2001.

Schirrmeister, B. E., de Vos, J. M., Antonelli, A., and Bagheri, H. C.: Evolution of multicellularity coincided with increased diversification of cyanobacteria and the Great Oxidation Event, P. Natl. Acad. Sci. USA, 110, 1791-1796, 2013.

Schopf, J. W.: Fossil evidence of Archaean life, Philos. T. Roy. Soc. B, 361, 869-885, 2006

Schopf, J. W., Kudryavtsev, A. B., Czaja, A. D., and Tripathi, A. B.: Evidence of Archean life: Stromatolites and microfossils, Precambrian Res., 158, 141-155, 2007. 
Scott, C. and Glasspool, J.: The diversification of Paleozoic fire systems and fluctuations in atmospheric oxygen concentration, P. Natl. Acad. Sci. USA, 103, 10861-10865, doi:10.1073/pnas.0604090103, 2006.

Sergeev, V. N., Gerasimenko, L. M., and Zavarzin, G. A.: Proterozoic history and present state of cyanobacteria, Mikrobiologiia, 71, 725-740, 2002.

Serrano-Andrés, L. and Merchán, M.: Are the five natural DNA/RNA base monomers a good choice from natural selection? A photochemical perspective, J. Photoch. Photobio. C, 10, 21-32, 2009.

Sessions, A. L., Doughty, D. M., Welander, P. V., Summons, R. E., and Newman, D. K.: The continuing puzzle of the Great Oxidation Event, Curr. Biol., 19, R567-R574, 2009.

Shick, J. M. and Dunlap, W. C.: Mycosporine-like amino acids and related gadusols: biosynthesis, accumulation, and UV-protective function in aquatic organisms, Annu. Rev. of Physiol., 64, 223 262, 2002.

Siggel, U., Bindig, U., Endisch, C., Komatsu, T., Tsuchida, E., Voigt, J., and Fuhrhop, H. J.: Photophysical and photochemical properties of porphyrin aggregates, Ber. Bunsenges. Phys. Chem., 100, 2070-2075, 1996.

Sigma-Aldrich: Thiamine hydrochloride product information, available at: http://www.sigmaaldrich.com/content/dam/ sigma-aldrich/docs/Sigma-Aldrich/Product_Information Sheet/t4625pis.pdf, last access: 25 January 2014a.

Sigma: Folic acid product information, available at: http://www.sigmaaldrich.com/content/dam/sigma-aldrich/ docs/Sigma/Product_Information_Sheet/f8758pis.pdf, last access: 25 January 2014 b.

Simionescu, C. I., Simionescu, B. C., Mora, R., and Leanca, M.: Porphyrin-like compounds genesis under simulated abiotic conditions, Orig. Life, 9, 103-114, 1978.

Smith, D. S., Scalo, J., and Wheeler, J. C.: Transport of ionizing radiation in terrestrial-like exoplanet atmospheres, Icarus, 171, 229-253, 2004.

Som, S. M., Catling, D. C., Harnmeijer, J. P., Polivka, P. M., and Buick, R.: Air density 2.7 billion years ago limited to less than twice modern levels by fossil raindrop imprints, Nature, 484, 359-362, 2012.

Stafford, H. A.: Anthocyanins and betalains: evolution of the mutually exclusive pathways, Plant Sci., 101, 91-98, 1994.

Stanley, S. M.: Earth System History, 3rd edn., W. H. Freeman and Company, New York, NY, 263-287, 2008.

Stoebe, B. and Kowallik, K. V.: Gene-cluster analysis in chloroplast genomics, Trends Genet., 15, 344-347, 1999.

Stomp, M., Huisman, J., Stal, L. J., and Matthijs, H. C.: Colorful niches of phototrophic microorganisms shaped by vibrations of the water molecule, ISME J., 1, 271-282, 2007.

Summons, R. E., Jahnke, L. L., Hope, J. M., and Logan, G. A.: 2-Methylhopanoids as biomarkers for cyanobacterial oxygenic photosynthesis, Nature, 400, 554-557, 1999.

Suo, Z., Avci, R., Schweitzer, M. H., and Deliorman, M.: Porphyrin as an ideal biomarker in the search for extraterrestrial life, Astrobiology, 7, 605-615, 2007.

Suttie, J. W.: Vitamin K in Health and Disease (Oxidative Stress and Disease), 1st edn., CRC Press, Taylor \& Francis Group, Boca Raton Florida, 31-33, 2009.
Szostak, J. W.: The eightfold path to non-enzymatic RNA replication, J. Sys. Chem., 3,2, 2012.

Szutka, A.: Porphine-like substances: probable synthesis during chemical evolution, Nature, 202, 1231-1232, 1964.

Tappert, R., McKellar, R. C., Wolfe, A. P., Tappert, M. C., OrtegaBlanco, J., Muehlenbachs, K.: Stable carbon isotopes of C3 plant resins and ambers record changes in atmospheric oxygen since the Triassic, Geochim. Cosmochim. Ac., 121, 240-262, 2013.

Theobald, D. L.: A formal test of the theory of universal common ancestry, Nature, 465, 219-222, 2010.

Tian, F., Toon, O. B., Pavlov, A. A., and De Sterck, H.: A hydrogen rich early Earth atmosphere, Science, 308, 1014-1017, doi:10.1126/science.1106983, 2005.

Tice, M. M. and Lowe, D. R.: Photosynthetic microbial mats in the 3416-Myr-old ocean, Nature, 431, 549-552, 2004.

Tice, M. M. and Lowe, D. R.: Hydrogen-based carbon fixation in the earliest known photosynthetic organisms, Geology, 34, 3740, 2006.

Trainer, M. G., Pavlov, A. A., DeWitt, H. L., Jimenez, J. L., McKay, C. P., Toon, O. B., and Tolbert, M. A.: Organic haze on titan and the early Earth, P. Natl. Acad. Sci. USA, 103, 18035-18042, 2006.

Tomitani, A., Okada, K., Miyashita, H., Matthijs, H. C., Ohno, T., and Tanaka, A.: Chlorophyll $b$ and phycobilins in the common ancestor of cyanobacteria and chloroplasts, Nature, 400, 159$162,1999$.

Toulmé, J. J., Charlier, M., and Héléne, C.: Specific recognition of single-stranded regions in ultraviolet-irradiated and heatdenatured DNA by tryptophan-containing peptides, P. Natl Acad. Sci. USA, 71, 3185-3188, 1974.

Unrau, P. J. and Bartel, D. P.: RNA-catalysed nucleotide synthesis, Nature, 395, 260-263, 1998.

Vekshin, N. L.: Photonics of Biopolymers, Springer, Berlin, Heidelberg, 2002.

Wang, J., Bras, R. L., Lerdau, M., and Salvucci, G. D.: A maximum hypothesis of transpiration, J. Geophys. Res., 112, G03010, doi:10.1029/2006JG000255, 2007.

Wang, M., Yafremava, L. S., Caetano-Anollés, D., Mittenthal, J. E., and Caetano-Anollés, G.: Reductive evolution of architectural repertoires in proteomes and the birth of the tripartite world, Genome Res., 17, 1572-1585, 2007.

White III, H. B.: Coenzymes as fossils of an earlier metabolic state, J. Mol. Evol., 7, 101-104, 1976.

Wiechert, U. H.: Earth's early atmosphere, Science, 298, 23412342, 2002.

Woese, C. R. and Gupta, R.: Are archaebacteria merely derived “prokaryotes"?, Nature, 289, 95-96, 1981.

Woutersen, S. and Cristalli, G.: Strong enhancment of vibrational relaxation by Watson-Crick base pairing, J. Chem. Phys., 121, 5381-5386, 2004.

Yarus, M., Widmann, J. J., and Knight, R.: RNA-amino acid binding: a stereochemical era for the genetic code, J. Mol. Evol., 69, 406-429, 2009.

Young, G. M., von Brunn, V., Gold, D. J. C., and Minter, W. E. L.: Earth's oldest reported glaciation: physical and chemical evidence from the Archean Mozaan Group (similar to $2.9 \mathrm{Ga}$ ) of South Africa, J. Geol., 106, 523-538, 1998. 
Zalar, A., Tepfer, D., Hoffmann, S. V., Kollmann, A., and Leach, S.: VUV-UV absorption spectroscopy of DNA and UV screens suggests strategies for UV resistance during evolution and space travel, Proc. of SPIE, 6694, Instruments, Methods, and Missions for Astrobiology X, 66940U (October 01, 2007); edited by: Hoover, R. B., Levin, G. V., Rozanov, A. Y., and Davies, P. C. W., San Diego, CA, doi:10.1117/12.733699, 2007.
Zollinger, H.: Color Chemistry: Syntheses, Properties, and Applications of Organic Dyes and Pigments, Verlag Helvetica Chimica Acta, Zürich, 15-65, 2003.

Zvezdanović, J. and Marković, D.: Bleaching of chlorophylls by UV irradiation in vitro: the effects on chlorophyll organization in acetone and $n$-hexane, J. Serb. Chem. Soc., 73, 271-282, 2008. 